\title{
Arqueología de Los Toldos y El Ceibo (provincia de Santa Cruz, Argentina)
}

Augusto CARDich $^{1}$

\section{Introducción}

Nuestras investigaciones arqueológicas en la Patagonia argentina empiezan en el año 1971. El área que estamos estudiando corresponde a la Patagonia extraandina, en la meseta central del norte de la provincia de Santa Cruz, al sur del río Deseado, incluyendo también la costa atlántica de la misma latitud, esto es, al norte del puerto San Julián. Las principales localidades que están siendo estudiadas son: Los Toldos, El Ceibo, La María y Playa Grande. Los resultados los hemos ido volcando, aunque en forma sucinta, en revistas de la especialidad (Cardich et al. 1973, 1977, 1982; Cardich 1977, 1978, 1979, 1984, 1985; Cardich y Flegenheimer 1978; Cardich y Miotti 1983; Cardich y Laguens 1984).

En el presente trabajo, reuniremos los principales datos y conclusiones, también en forma sumaria, que hemos ido obteniendo sobre la base de la secuencia determinada en la Cueva 3 de Los Toldos. Se agregarán también los datos más relevantes de la secuencia de la Cueva 7 de El Ceibo y algunos adelantos de las recientes excavaciones en las Cuevas 2 y 13 de Los Toldos.

\section{Ubicación de los yacimientos y breve descripción del ambiente}

La localidad de Los Toldos está situada a $47^{\circ} 28^{\prime}$ Lat. S y $68^{\circ} 50^{\prime}$ Long. O y El Ceibo a $48^{\circ} 31^{\prime}$ 'Lat. S y $68^{\circ} 45^{\prime}$ de Long. O. Fisiográficamente, las zonas de ambos yacimientos poseen las características de la Patagonia extraandi-na, con mesetas amplias, recortadas por cursos de agua temporarios, que forman cañadones, como en el caso de Los Toldos en el paraje denominado Cañadón de las Cuevas (Figura 1) de la estancia Los Toldos; o de los llamados bajos, que son depresiones que forman cuencas de drenaje centrípeto como en El Ceibo,

1 Museo de La Plata. La Plata. ARGENTINA. con cavernas justamente en los acantilados de un bajo, dentro del perímetro de la estancia El Ceibo (Figura 2).

En cuanto al clima actual, nos podemos orientar mediante los datos obtenidos para la zona de Los Toldos: temperatura media anual de $9.7^{\circ} \mathrm{C}$, con máximas y mínimas absolutas de $35.1^{\circ} \mathrm{C}$ y $-19.4^{\circ} \mathrm{C}$, respectivamente. Le corresponde la isoterma de enero de $16^{\circ} \mathrm{C}$ y la de julio de $2^{\circ} \mathrm{C}$. Las precipitaciones alcanzan una media anual de $161 \mathrm{~mm}$ y la humedad promedio de $55 \%$. Los vientos tienen una media anual de $17 \mathrm{~km}$ por hora, predominando durante todos los meses los del oeste. Estas condiciones conforman, naturalmente, un clima frío, seco y ventoso, típico de la árida-semiárida estepa patagónica.

El cauce del Cañadón en Los Toldos está constituido por rellenos fluviátiles de un pequeño arroyo temporario, y los flancos rocosos -que contienen las cavernas- de sedimentitas piroclásticas bien consolidadas de color ocre pálido, aspecto pumíceo y textura porfírica, que corresponde al Complejo Porfírico o Formación Chon Aike. Tienen igual formación los acantilados rocosos en los que se alojan las cavernas de El Ceibo. Observadas microscópicamente, las rocas pueden clasificarse como tobas vítreas con pastas muy alteradas (devitrificadas).

Desde el punto de vista biogeográfico corresponde al Distrito Patagónico Central de la Provincia Patagónica (Cabrera y Willink 1980: 93-94). Mayormente se encuentra una vegetación de estepa arbustiva; presenta menor cobertura en las mesetas, donde destacan por su adaptación a los fuertes vientos los subarbustos de hojas resinosas y coriáceas, en forma de cojines, rosetas o alfombras que recuerdan a especies de las grandes altitudes de los Andes. Las asociaciones de arbustos y gramíneas se hacen más densas en los cañadones y en ciertos sectores de los bajos. Asimismo se advierte un incremento de gramíneas y ciperáceas en las zonas de mayor humedad y en los fondos de valles y cañadones. 


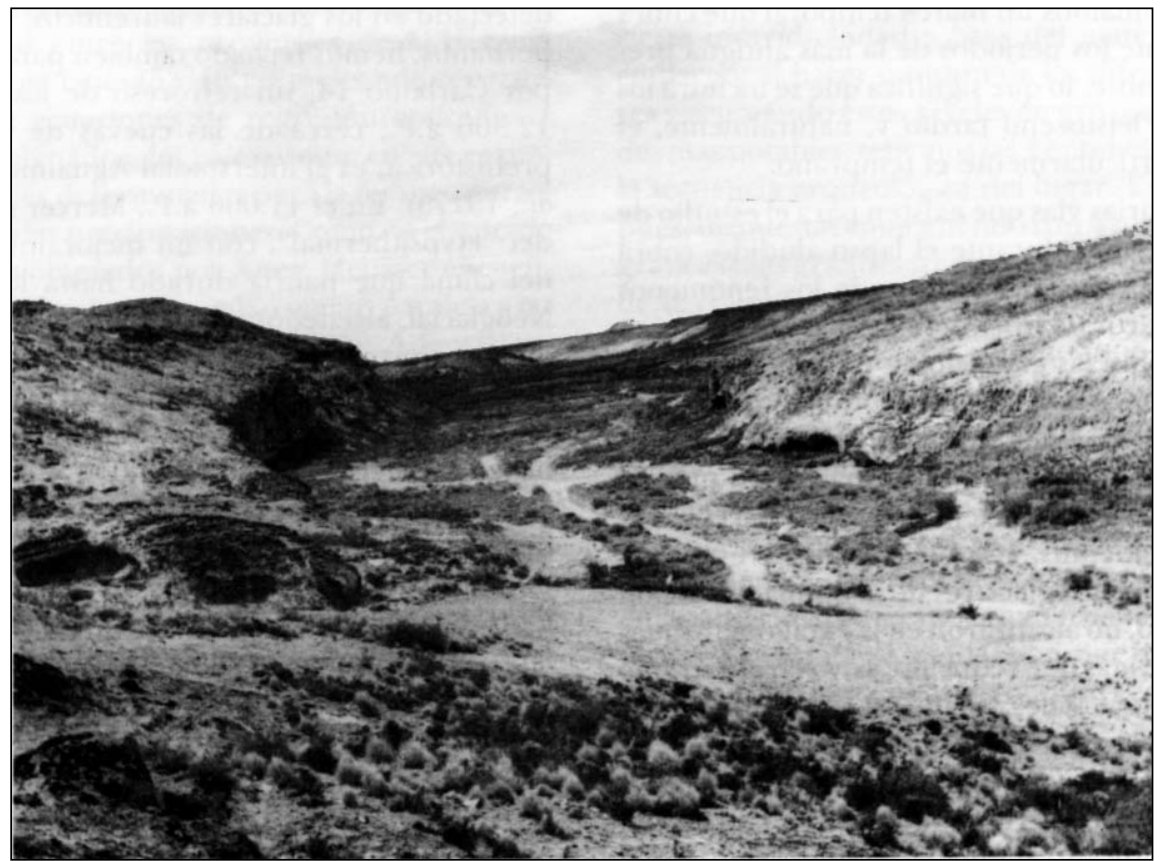

Figura 1. Vista del Cañadón de las Cuevas, en la estancia Los Toldos, en el que se encuentran las cavernas de ocupación prehistórica.

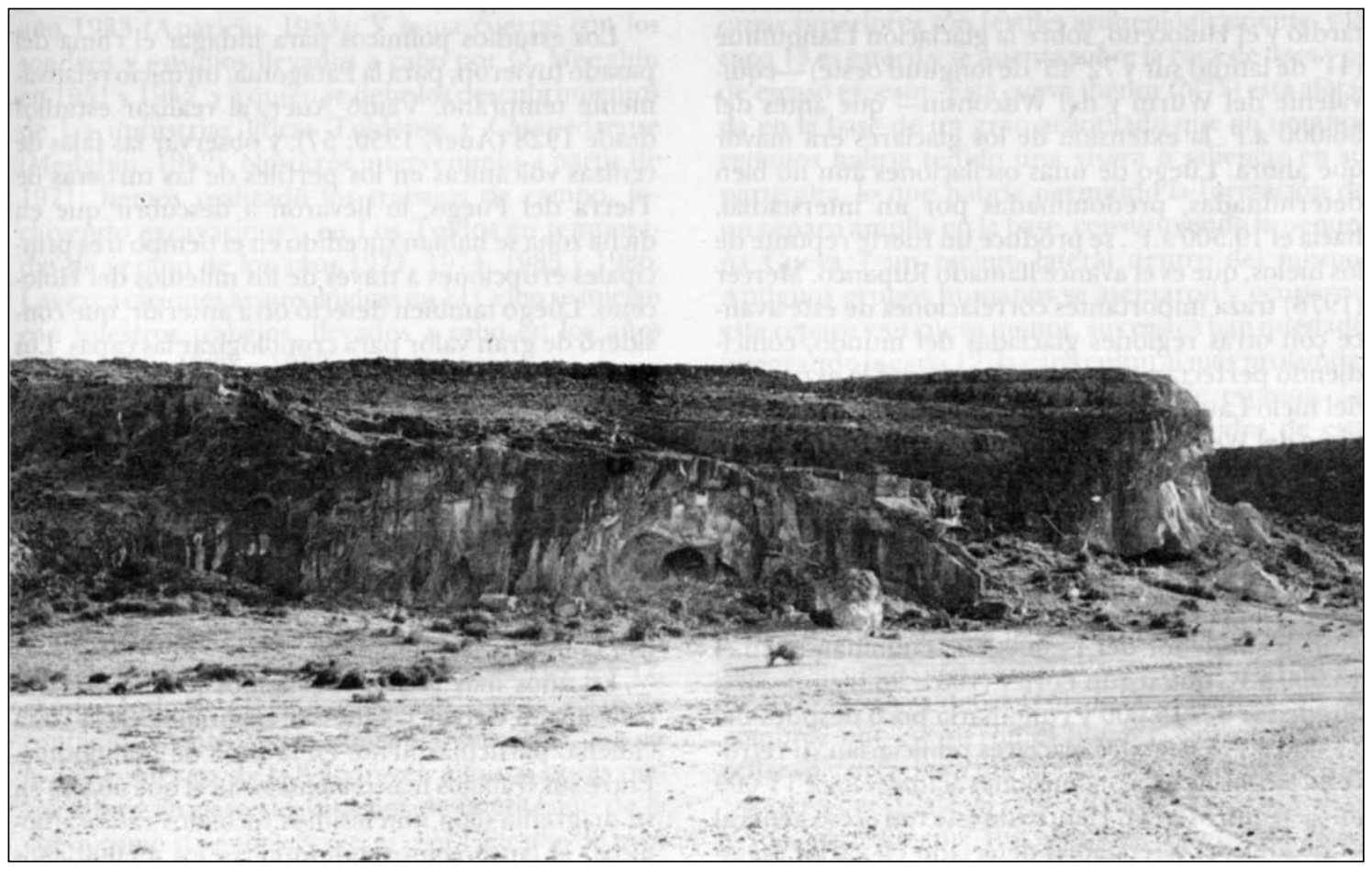

Figura 2. El acantilado que contiene las cuevas en la zona de El Ceibo. 
Dentro de la fauna que se puede relacionar con nuestros estudios destaca fundamentalmente el guanaco (Lama guanicoe), de notable importancia. Entre las aves, el ñandú (Pteronemia pennata), eventualmente aparece el llamado ñandú de las pampas (Rhea americana), cuyo hábitat original está más al norte. Asimismo se encuentra la martineta común de la subespecie Eudromia elegans patagonica, con presencia registrada hasta el río Santa Cruz (Navas y Bo 1981). Se hallaron también pocos huesos de roedores.

\section{Los paleoambientes}

Para aproximarnos a este tema relacionado con la prehistoria, tomamos un marco temporal que cubre suficientemente los períodos de la más antigua presencia del hombre, lo que significa que se incluirán el Pleistoceno Tardío y, naturalmente, el Holoceno, particularmente el Temprano.

Entre las varias vías que existen para el estudio de los paleoambientes durante el lapso aludido, cobra principal importancia el estudio de los fenómenos glaciares. A partir de fines del siglo pasado aparecen referencias sobre las glaciaciones de la Patagonia en escritos de Moreno, Nordenskjold, Hauthal, Steinmann y otros. Empero, los estudios fundamentales se producen hace algo más de medio siglo, a cargo del científico sueco Caldenius (1932). A partir de estos trabajos se sabe que los glaciares de la última glaciación del Pleistoceno no alcanzaron en la Patagonia argentina un avance más que reducido, salvo en el extremo austral. Investigaciones posteriores han ido confirmando parcialmente estas conclusiones, como las realizadas por Flint y Fidalgo $(1963,1968)$, entre los paralelos $39^{\circ} 10^{\prime}$ y $43^{\circ} 10^{\prime}$. Sin embargo, la datación del límite adjudicado al Finiglacial por Caldenius ha sido rectificada, para un estadio anterior, de acuerdo a los fechados obtenidos por Auer (1956: 217-218) y por Mercer (1970: 19-20). Entre los trabajos recientes para esta región austral de América del Sur, corresponde destacar los de Mercer (1970, 1972, 1976) y Porter (1981), entre otros. Extrayendo las principales conclusiones de Mercer, podemos recordar para el Pleistoceno Tardío y el Holoceno, sobre la glaciación Llanquihue $\left(41^{\circ}\right.$ Lat. S y $72^{\circ} 45^{\prime}$ Long. O) -equivalente del Würm y del Wisconsin-que antes del 56000 AP la extensión de los glaciares era mayor que ahora. Luego de unas oscilaciones aún no bien determinadas, predominadas por un interstadial, hacia el $19500 \mathrm{AP}$, se produce un fuerte repunte de los hielos, que es el avance llamado Rupanco. Mercer (1976) traza importantes correlaciones de este avance con otras regiones glaciadas del mundo, coincidiendo perfectamente en el tiempo con la expansión del hielo Laurentico en Norteamérica, el avance máximo del Weichsel en la morrena Branderburg de los glaciares escandinavos y con el avance Otirán tardío de Nueva Zelanda. Luego del avance Rupanco deviene un retroceso que se centra alrededor de los 16200 años AP, llamado interstadial Varas, que también posee claras correlaciones. Habría luego un nuevo avance alrededor del 14000 AP, culminando en el 13000 AP, que según Porter (1981: 263) empezaría alrededor del 15000 y culminaría poco después del 13000 AP. Luego los glaciares reiniciarían su retroceso, alcanzando las extensiones actuales hace 11000 años, según Mercer. Dentro de este retroceso general se incluiría el interstadial detectado en varias regiones, como el Bolling de Escandinavia, o del retroceso detectado en los glaciares laurenticos. En los Andes peruanos hemos fechado también para Lauricocha, por $\mathrm{C}^{14}$, un retroceso de los hielos en el $12500 \mathrm{AP}$, cerca de las cuevas de la ocupación prehistórica; es el interstadial Aguamiro (Cardich et al. 1977a). En el 11000 AP, Mercer sitúa el inicio del Hypsithermal, con un mejoramiento térmico del clima que habría durado hasta los inicios del Neoglacial, alrededor de los 4500 AP, período éste que se caracteriza por avances y retrocesos glaciarios de carácter más bien moderado. En este esquema de Mercer no aparece el posible avance glaciar que pudo haber acontecido entre 11000 y 10000 AP, equivalente al Dryas reciente de Europa o al Valders de Norteamérica. Sin embargo, de acuerdo a los estudios palinológicos de Heusser para la misma región chilena, se ha determinado para el mencionado lapso un enfriamiento climático, con una temperatura media con $3^{\circ} \mathrm{C}$ por debajo de la actual. Asimismo, en los centros de glaciaciones en los Andes peruanos, como en Vilcanota y Lauricocha, y también en Colombia y Venezuela, se han detectado avances del hielo para dicho momento. Ahora bien, estas investigaciones vinculadas con el glaciarismo y la cronología de sus oscilaciones son importantes para estructurar el armazón cronológico y paleoambiental de los acontecimientos prehistóricos. Empero, las zonas de nuestro estudio han estado libres de la acción directa de las glaciaciones, y no ha constituido ningún impedimento o barrera que hubiera obstaculizado la presencia del hombre.

Los estudios polínicos para indagar el clima del pasado tuvieron, para la Patagonia, un inicio 
relativamente temprano. Auer, al realizar estudios desde 1928 (Auer 1950: 57), y observar las fajas de cenizas volcánicas en los perfiles de las turberas de Tierra del Fuego, lo llevaron a descubrir que en dicha zona se habían sucedido en el tiempo tres principales erupciones a través de los milenios del Holoceno. Luego también detectó otra anterior, que consideró de gran valor para cronologizar las capas. Los sedimentos o capas intercalados entre capas de cenizas que se llamaban lapsos, están hoy cronologizados por $\mathrm{C}^{14}$. Al estudiarse el contenido polínico de estas turberas, los diagramas indicaban la lucha del bosque y la estepa, como una expresión de los cambios climáticos ocurridos. Auer comparó sus resultados con los del sistema europeo del Holoceno, y al encontrar paralelismos en las variaciones usó la misma terminología.

En años más recientes tenemos los importantes trabajos de Heusser realizados en la costa chilena, particularmente en la zona de Llanquihue. Entre sus trabajos más recientes está el que abarca en su diagrama (con muchísimos fechados radiocarbónicos) el lapso comprendido entre los 43000 años AP y la actualidad (Heusser y Streeter 1980; Heusser 1983), efectuado mediante investigaciones en diversos sitios entre las provincias de O'Higgins $\left(34^{\circ} 30^{\prime}\right)$ y Magallanes ( $\left.53^{\circ} 40^{\prime}\right)$. Empleando recursos estadísticos y ecuaciones de regresión aplicados a registros combinados, logró expresar en sus esquemas variaciones determinadas para la temperatura y también para las precipitaciones. Como en el caso de los resultados obtenidos por Auer, Heusser encuentra una evolución climática más o menos paralela a las determinadas para el hemisferio norte. Además, estos esquemas palinológicos coinciden en gran parte con los datos obtenidos por los estudios paleoglaciológicos de la región.

En la Patagonia argentina adquiere importancia, asimismo, el fenómeno de la eustasia glacial. La costa oriental posee una amplia plataforma que está sumergida. Existen fechados por $\mathrm{C}^{14}$ realizados hace más de 20 años, que están consignados en los trabajos de Fray y Ewing (1963).

\section{Exposición sumaria de las investigaciones}

Veamos ahora aspectos principales de los estudios arqueológicos. Estos se realizaron en las localidades de Los Toldos, cuyos datos nos han servido de base para nuestro esquema, agregándose los principales conocimientos adquiridos en la Cueva 7 de El
Ceibo. La mención de Los Toldos en la bibliografía arqueológica empieza luego de la breve visita a la zona por los investigadores Aparicio y Frenguelli en 1933 (Aparicio 1933). Y toma cuerpo con los sondeos y estudios llevados a cabo por Menghin en 1951 y 1952, y a quien se deben los descubrimientos de las industrias líticas Toldense y Casapedrense (Menghin 1952). Nosotros intervenimos a partir de 1971 realizando los trabajos de campo, incluyendo excavaciones en Los Toldos en temporadas de verano de los años 1971, 1974, 1985 y 1986. Las excavaciones arqueológicas en El Ceibo se inician con nuestros trabajos, llevados a cabo en los años 1979, 1980, 1982 у 1983.

En nuestro primer informe (Cardich et al. 1973) dimos a conocer la secuencia arqueológica más notable de Los Toldos, que coincidía con estratos naturales más importantes de la columna estratigrática de la Cueva 3. En esta caverna se descubrieron 12 capas naturales, llegando a una profundidad máxima de $1.80 \mathrm{~m}$ en la excavación de 1971 y $2 \mathrm{~m}$ en la de 1974. De estas 12 unidades estratigráficas, ocho fueron fértiles, exceptuándose las capas $4,5,8$ y 12 , comenzando de arriba hacia abajo, que carecían de contenido arqueológico, debiendo aclararse que en la parte inferior de la 8 aparecen algunas pocas piezas líticas, empero sin vestigios de la posesión de la cueva como vivienda al carecer, por ejemplo, de huellas de fogones. Las ocho capas fértiles poseen características más o menos particulares, presentando una cierta individualidad a base del material lítico. Sin embargo, al hacer omisión de las diferencias menores y reuniendo estos niveles en grupos, por similitudes más notables, tenemos las cuatro entidades mayores de la secuencia arqueológica del lugar. Estas aparecen, pues, dispuestas coincidiendo con cuatro unidades estratigráficas más grandes o espesas y a la vez significativas de la columna estratigráfica.

En cuanto a El Ceibo, diremos que igual que Los Toldos corresponde a zonas arqueológicas de antiguos cazadores y recolectores en la llamada meseta central patagónica. La presencia de numerosas expresiones de arte rupestre en sus cuevas y reparos, sumada a la riqueza en implementos líticos, que se advierte en los sedimentos de muchas de sus cuevas, y en la superficie de grandes extensiones, como característica más notable en El Ceibo, que no es común en otros yacimientos, estaría configurando uno de los centros prehistóricos más relevantes del continente. El sector principal de los yacimientos de El Ceibo se 
ubica en el lado septentrional de un bajo de varios kilómetros de diámetro. La profundidad de dicho bajo es de $65 \mathrm{~m}$, por lo que corresponde a los llamados "wannen" de las sistematizaciones presentadas por Fidalgo (1973: 131). Hemos realizado sondeos y excavaciones en varias de sus cuevas y reparos. El perfil más completo y con clara estratificación lo encontramos en la pequeña Cueva 7. Aquí separamos 13 capas naturales, desde la superficie hasta la roca de base, en una profundidad de $1.50 \mathrm{~m}$. Las 12 capas superiores son fértiles arqueológicamente, y la capa 13 es estéril y se asienta sobre la roca de base y es de escaso espesor. Esta cueva menor $\left(\mathrm{n}^{\circ} 7\right)$ está alojada en la base de un gran acantilado que en tiempos remotos habría tenido una visera o saliente en su parte alta, lo que habría permitido la formación de un reparo amplio en la base, constituyendo la pequeña Cueva 7 un recinto lateral dentro del mismo. Antiguos grupos humanos se asentaron y ocuparon este reparo y su cueva menor, sus restos han quedado integrando la capa 12, la capa cultural más profunda, de aproximadamente 15 a $20 \mathrm{~cm}$ de espesor. La colección de implementos líticos obtenidos de esta capa 12 es similar a la industria del nivel 11 de Los Toldos (Cardich et al. 1982; Mansur-Franchomme 1984). Es similar también la asociación, particularmente por existir en ambos yacimientos huesos de caballo prehistórico y de un camélido extinguido (Lama gracilis), aparte de elementos de la fauna actual. Sobre esta capa 12 cayó un tremendo derrumbe de toda la visera del acantilado, con piedras y escombros que cubrieron el lugar y, por otra parte, sellaron perfectamente la capa 12; sin embargo, la pequeña cueva lateral (7) se libró de estos escombros y sólo parcialmente fue afectada. Es en esta cueva menor donde se continúa claramente la superposición de los estratos finos y fértiles hasta el presente. En estos niveles por encima de la capa 12 se han encontrado artefactos asimilables a la industria Toldense, como unos fragmentos de puntas finamente trabajadas en la capa 9. La presencia Casapedrense es escasa, asimismo en los hallazgos de superficie, mucho menor que en Los Toldos. En los niveles superiores y más recientes hay algunas piezas equivalentes a las industrias de los niveles 1 , 2 y 3 de Los Toldos.

Ahora bien, como una forma de presentar una secuencia arqueológica más o menos representativa de esta zona de la meseta central patagónica, veamos la determinada para Los Toldos reunidos en el siguiente esquema: a) Niveles industriales 1,2 y 3

Están contenidos en las capas 1, 2 y 3. A pesar de que incluye la superficie actual del piso de la Cueva 3 , no contiene restos arqueológicos muy recientes de la Patagonia prehispánica. Carece, por ejemplo, de cerámica. Faltan asimismo las puntas de flechas pequeñas. La industria lítica descubierta en estas capas contiene lascas y láminas, raspadores mayormente cortos, pocas raederas y éstas de morfología dudosa. El conjunto destaca porque aparecen algunas piezas bifaciales, como puntas, casi todas fragmentadas, con excepción de unas pocas enteras. Se levantaron también dos placas grabadas. Esta industria lítica así como los desechos de alimentación estarían señalando una economía de cazadores. La presa principal fue el guanaco (Lama guanicoe), pero no en forma exclusiva, pues se advierte la presencia de restos óseos de otras especies, como huesos de ñandú, zorrino, algunos pocos de Cervidae y hasta se levantaron dos fragmentos de valvas de moluscos del Atlántico. En cuanto a la densidad de población, se deduce que hubo una mayor presencia en la capa 3 , disminuyendo en la 2 para ser escasa en la 1 . Sobre la cronología de los inicios de esta ocupación podemos estimar que ella se produce alrededor de los 4000 años AP, como explicaremos más adelante al referirnos a la ocupación Casapedrense.

\section{b) Niveles 6 y 7 o Casapedrense}

La industria Casapedrense fue descubierta y descrita por Menghin en las cuevas 2 y 3 de Los Toldos. Particularmente en el perfil de esta última cueva señaló la presencia Casapedrense en los niveles intermedios y superiores (Menghin 1952: 39), y nosotros hemos circunscrito solamente para las capas 6 y 7 (aproximadamente equivalente a los niveles intermedios de Menghin). El Casapedrense es una industria fundamentalmente de láminas; estas láminas generalmente poseen filos naturales agudos y un buen porcentaje presenta retoques unifaciales en sus bordes. Comprende esta industria varios tipos de raspadores, generalmente alargados, y entre éstos destacan los de borde distal oblicuo, los de bisel obtuso y los cuadrangulares. Contiene cuchillos, las raederas son escasas y las pocas son de morfología dudosa. Se han encontrado también algunas boleadoras y fragmentos de éstas. Lo notable es que hay ausencia completa de puntas líticas de proyectil, rasgo que queda definidamente establecido teniendo en cuenta el gran número de piezas de esta industria obtenido en las excavaciones de los años 1971 y 1974, 
a los que se agrega la gran cantidad exhumada en las excavaciones más recientes. Estos formidables cazadores se especializaron en la caza del guanaco, que los restos óseos de este camélido aparecen casi en exclusividad y en cantidad muy importante. De acuerdo a recientes estudios de estos restos óseos de la Cueva 3 de Los Toldos, se puede decir que habrían aprovechado las presas en forma integral, por la presencia en capa de muchos fragmentos de huesos correspondientes a todo el conjunto esqueletario; por la determinación de huesos de individuos de diferentes edades se puede concluir que la cueva habría sido ocupada en todas las estaciones del año (Cardich y Miotti 1984: 154). Usaron boleadoras y posiblemente emplearon algunas otras técnicas, como trampas y también lazos, como vemos en el testimonio rupestre (Figura 15) en una cueva de La María, que aunque no estamos seguros de que pueda ser Casapedrense, al menos la técnica era conocida en la Patagonia. Podemos consignar, asimismo, que en la parte superior de la capa 6 de este mismo sitio de Los Toldos, o Casapedrense final, se hallaron huesos de Canis familiaris (Cardich et al. 1977), que habría constituido tal vez un buen auxiliar para la caza. $\mathrm{La}$ cronología de la ocupación Casapedrense de la Cueva 3 de Los Toldos está perfectamente determinada por dataciones radiocarbónicas: empieza la ocupación en $7260 \pm 350$ años AP (FRA-96) y finaliza en $4850 \pm 90$ años AP (LP-136), fecha esta última que confirma nuestras estimaciones anteriores y se suma en forma coherente a los fechados radiocarbónicos obtenidos para la secuencia de la Cueva 3 de Los Toldos (Cardich et al. 1973). La posesión Casapedrense fue la más densa del sitio, probablemente tuvieron condiciones favorables del clima (Cardich et al. 1973:103; Cardich 1984: 30, 31). En la Cueva 13, de $120 \mathrm{~m}$, ubicada en la base de un largo acantilado, hemos realizado últimamente cuatro excavaciones en diversos sectores, descubriendo una densa ocupación Casapedrense.

\section{c) Niveles 9 y 10 o Toldense}

Por debajo del Casapedrense (capas 6 y 7), se encuentra la capa 8 , que corresponde a un hiato en la ocupación humana de la cueva. En efecto, entre la fecha de $8750 \pm 480$ años AP (FRA-97), de una muestra de carbón de la cima de la capa 9 correspondiente al final de la ocupación Toldense, y la de 7260 350 años AP, de la primera ocupación Casapedrense, con muestra de la base de la capa 7, se extiende un lapso de 1490 años en que fue prácticamente abandonada la cueva, pues aparecen sólo algunos pocos artefactos
Toldense en la parte inferior de la capa 8, que quizás fueron dejados por cazadores asentados en otros lugares pero que ingresaban a guarecerse durante sus recorridos. Por debajo de este hiato constituido por la capa 8 , nos encontramos ya con los restos culturales de los más antiguos cazadores, pertenecientes, como dijimos, a la cultura Toldense (capas 9 y 10) y aun a mayor profundidad a la cultura del nivel 11 (capas 11a y 11b). Ambas culturas líticas corresponden perfectamente a la etapa paleoindia de esta parte de América, tanto por las características de sus industrias como por la datación radiocarbónica, así como también por los recursos faunísticos, en los cuales, aunque predominan representantes de la fauna actual, hay también restos de fauna extinguida. La cultura Toldense fue caracterizada por su descubridor, Menghin, quien destacó el carácter avanzado de su industria lítica, señalando que "abarca puntas de dardos de trabajo bifacial con pedúnculo pero sin aletas, un cuchillo largo con la misma técnica; raspadores de tamaño mediano y grandes de varios tipos..." (Menghin 1952: 37, 38). Las piezas de esta industria están mayormente realizadas sobre lascas. Aunque predominan los artefactos de retoque marginal, las piezas más elaboradas muestran una técnica muy depurada. Los retoques son resultado de trabajos cuidadosos, siendo frecuentes los retoques escamosos y paralelos. Hemos hallado puntas subtriangulares de escaso espesor (Figura 3), con finos trabajos a presión abarcando sus dos caras, también fragmentos de otras puntas bifaciales, entre estos un pedúnculo más o menos rectangular con la base ligeramente rebajada con finos trabajos a presión, acercándose a las formas encontradas en la capa I de Fell. Asimismo aparecen excelentes raederas, en proporción muy superior a los niveles anteriormente tratados. También raspadores finos y de varios tamaños; cuchillos de largas hojas trabajadas en sus dos caras, así como algunos fragmentos de piezas bifaciales grandes. Un hallazgo notable correspondió a una pieza discoidal alisada, de toba, similar a las encontradas por Menghin en este mismo nivel Toldense de Los Toldos y por Bird en la capa I de Fell (Bird 1970). Aparecieron algunos artefactos de hueso como retocadores y punzones finos, también unas pequeñas piezas tubulares de huesos de ave. Los desperdicios óseos de alimentación dejados por estos cazadores muestran una gama relativamente amplia de especies, diferenciándose notablemente en este aspecto de los Casapedrenses. Aparte del guanaco consumido en mayor proporción que las otras especies, se han determinado huesos de aves como ñandú (Rheidae) y de la Tinamidae conocida 


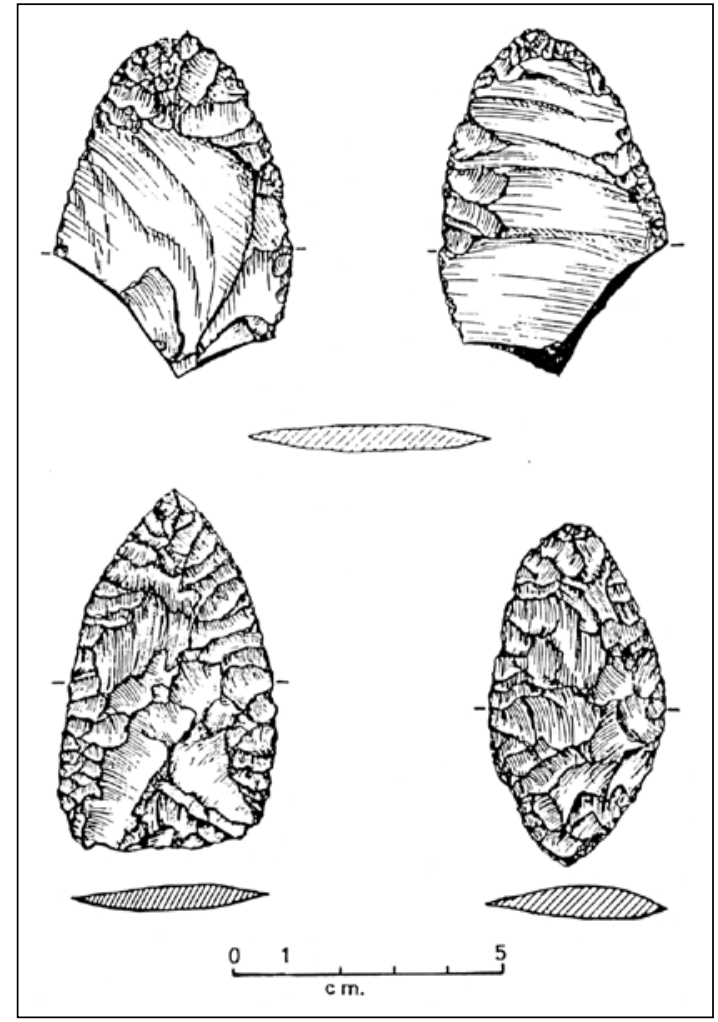

Figura 3. Puntas bifaciales de escaso espesor del nivel Toldense de Los Toldos.

como martineta (Eudromia sp.). Lo más notable es la presencia de huesos de caballo prehistórico, del género Onohippidion (Parahipparion) sp., que también encontramos en reciente trabajo en la Cueva 2. No faltaron huesos de roedores en escasa proporción de la famila Cavidae y asimismo de puma (Felis sp.). En cuanto a la referencia cronológica, de su finalización en la ocupación de la cueva, como ya dijimos, se produce alrededor de 8750 años AP, y para sus inicios estimamos una fecha cercana a los 11000 años AP, relacionando con la datación de Fell I (Cardich et al. 1973: 114-115). Su dispersión habría sido amplia en la Patagonia, y sus epígonos tardíos persistieron un tiempo más en otras zonas.

\section{d) Nivel 11}

En la secuencia estratigráfica de la Cueva 3 de Los Toldos, avanzando en profundidad, ante todo en algunas de las cuadrículas como a la entrada y en el lado derecho del recinto mayor, se encontró un estrato arqueológicamente fértil, la capa 11 (11a y $11 b)$, alternando con sedimentos estériles. Constituye la más antigua capa con contenido cultural, y al que llamamos nivel 11. La singularidad de esta industria -aunque conteniendo algunos rasgos que probablemente constituyen antecedentes de posteriores industrias como la Toldense- ha sido señalada a base de consideraciones tipológicas (Cardich et al. 1973, 1982; Cardich 1977; Cardich y Flegenheimer 1978; Mansur-Franchomme 1984). Aparte, como señalamos arriba, en la capa 12 de la Cueva 7 de El Ceibo, que contiene la industria similar a la del nivel 11 de Los Toldos, aparece sellada por los escombros de un antiguo derrumbe que ha circunscrito perfectamente su identidad (Cardich 1979). Las piezas de esta industria están constituidas por lascas de variado tamaño, destacando las grandes. Tomada en conjunto, es la industria que posee mayores dimensiones de todas del perfil. Sobresalen las lascas grandes, espesas, de forma y de contorno variables, retocadas en parte, y unifaciales (Figuras 4, 5 y 6); hay buena proporción de raederas (Figuras 5, 6 y 7) en mayor proporción comparado con las industrias anteriores, éstas son generalmente de bulbos prominentes; los raspadores son relativamente grandes (Figura 8), predominando los de borde activo menor que el ancho de la lasca. Algunas piezas finas contienen retoques delicados, inclusive unas pocas a presión; cuchillos unifaciales (Figura 9) y fragmentos de posibles puntas unifaciales. No hemos encontrado en Los Toldos (tampoco en las recientes campañas) piezas bifaciales, prácticamente tampoco en El Ceibo; sin embargo, en este yacimiento en los trabajos de 1982, en un extremo del sector del reparo,

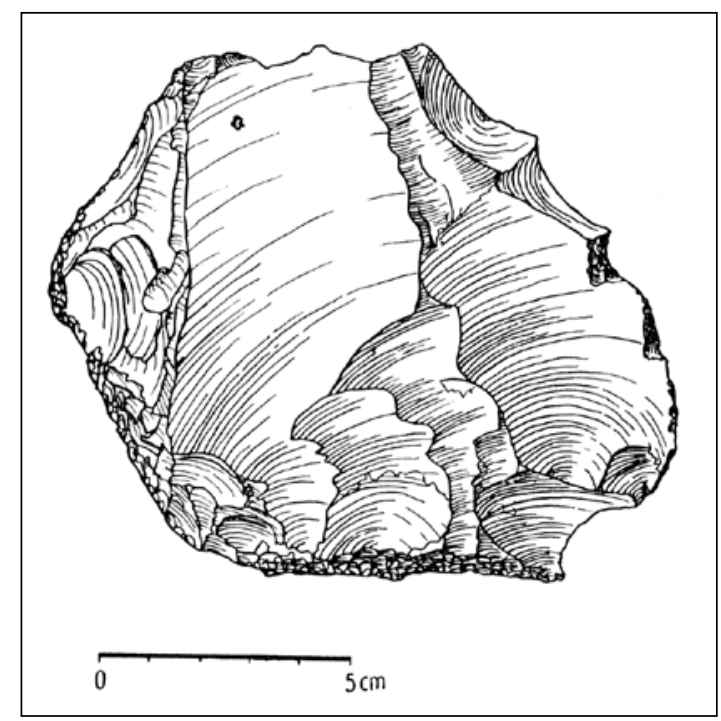

Figura 4. Lasca grande, espesa, de forma o contorno variable de El Ceibo. 


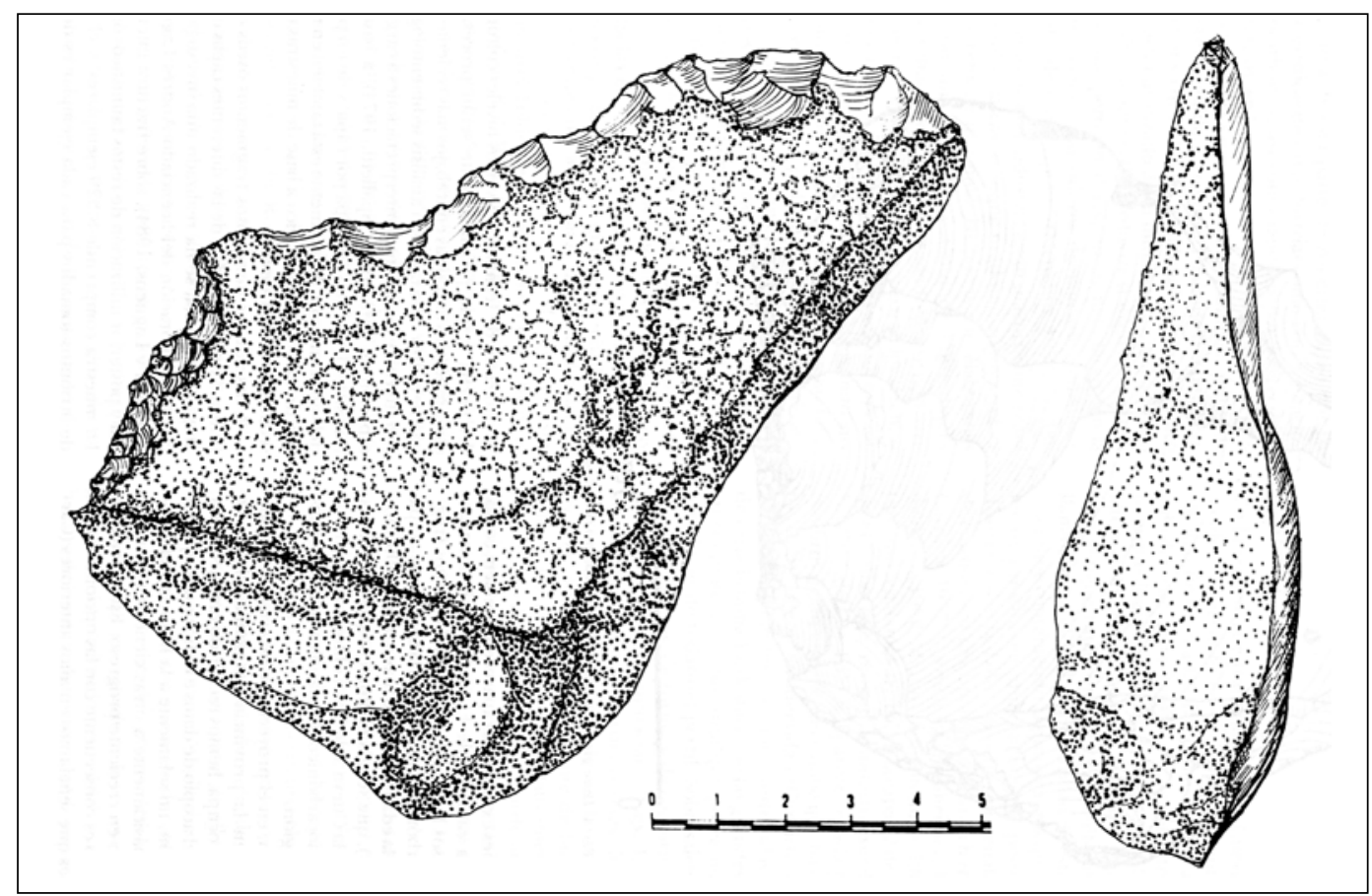

Figura 5. Lasca grande, espesa, de forma o contorno variable de Los Toldos, nivel 11.

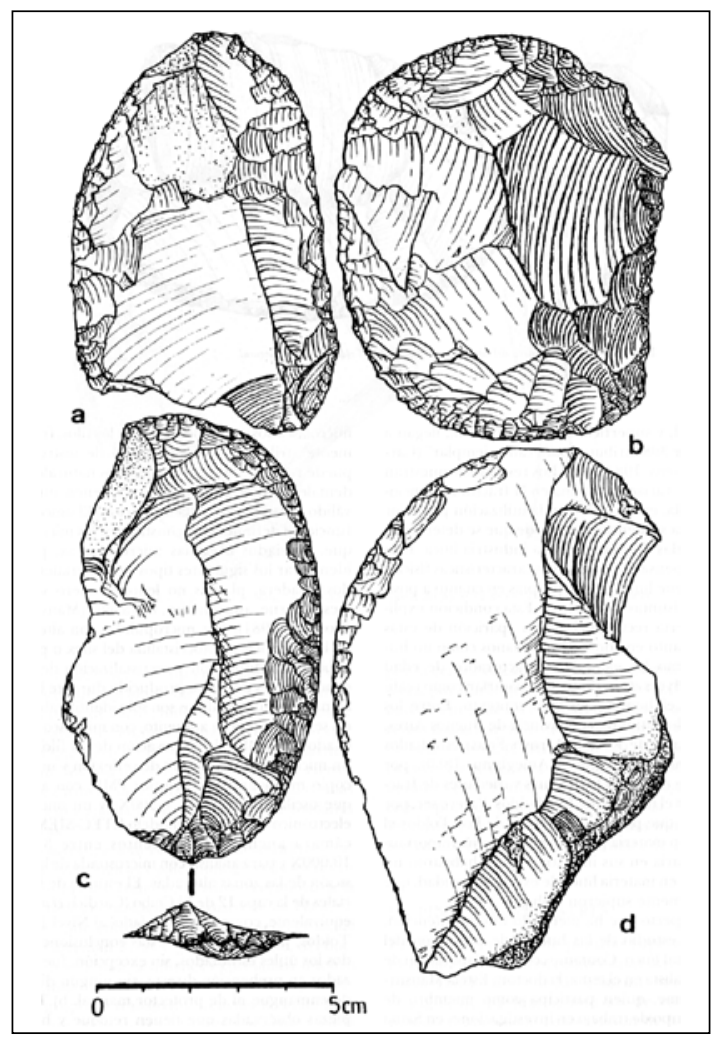

Figura 6. a) Raedera doble lateral (tipo $S$ ); b) Raedera perimetral; raedera simple lateral (tipo 0 ). Proceden a la capa 12 de la Cueva 7 de El Ceibo, nivel 11. encontramos en la capa 12 una pieza circular chata, trabajada en sus dos caras. De los escasos restos óseos fragmentados, probablemente residuos de alimentación, se pudo determinar una parte de ellos identificando una gama relativamente amplia de especies, entre ellos de guanaco (Lama guanicoe); de caballo prehistórico probablemente del género Onohippidion (Parahipparion) sp., extinguido en la meseta central patagónica hace aproximadamente 10000 años; algunos huesos de un camélido más grácil que el guanaco, que coincide con huesos de una especie identificada para el Pleistoceno Superior de la Pampa bonaerense por Ameghino (1889: 581) como Lama gracilis. Ambas especies aparecen también, como se dijo, en la capa 12 de El Ceibo. Se levantaron también escasos huesos de roedores. Pequeños fragmentos de carbón encontrados en la base de esta capa 11 arrojaron la edad de 12600 \pm 600 años AP (FRA-98), que señala el momento de la primera ocupación de la Cueva 3 de Los Toldos, y hasta ahora es el dato radiocarbónico de más alta edad determinada en la región.

Ahora bien, en el proyecto de investigaciones arqueológicas en la provincia patagónica de Santa Cruz, que nos ocupa, hemos recurrido también, para incrementar el acopio de datos e indicios que apoyen la investigación, no solamente a la historia 


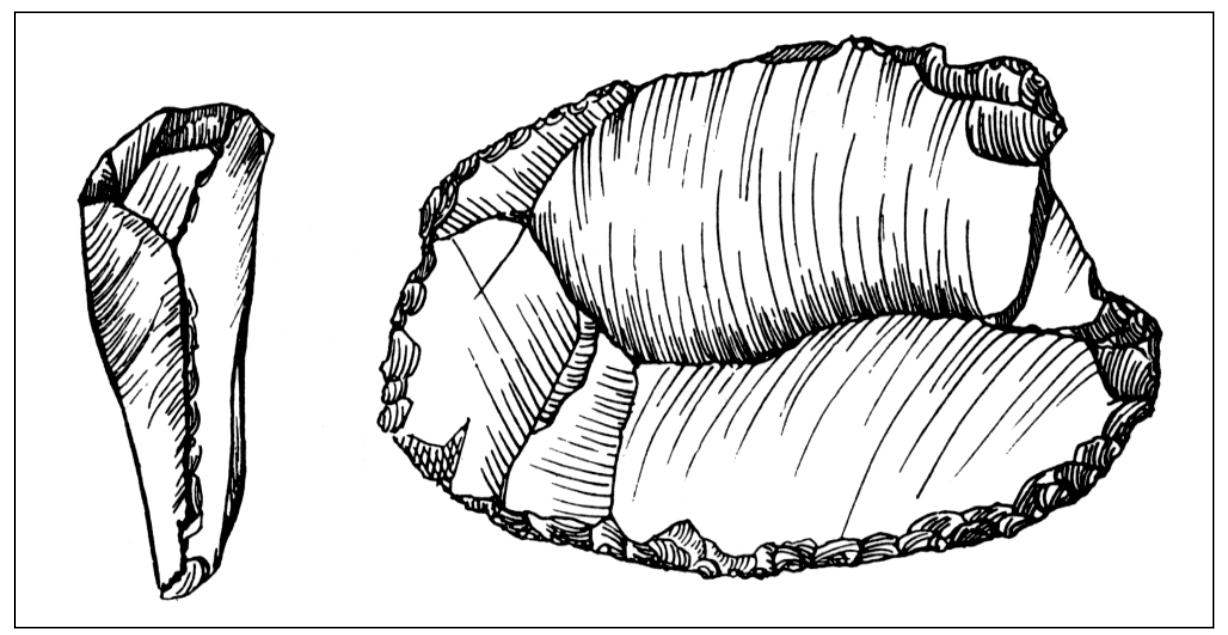

Figura 7. Lasca hecho raedera del tipo W. proviene de Los Toldos. Tamaño natural.

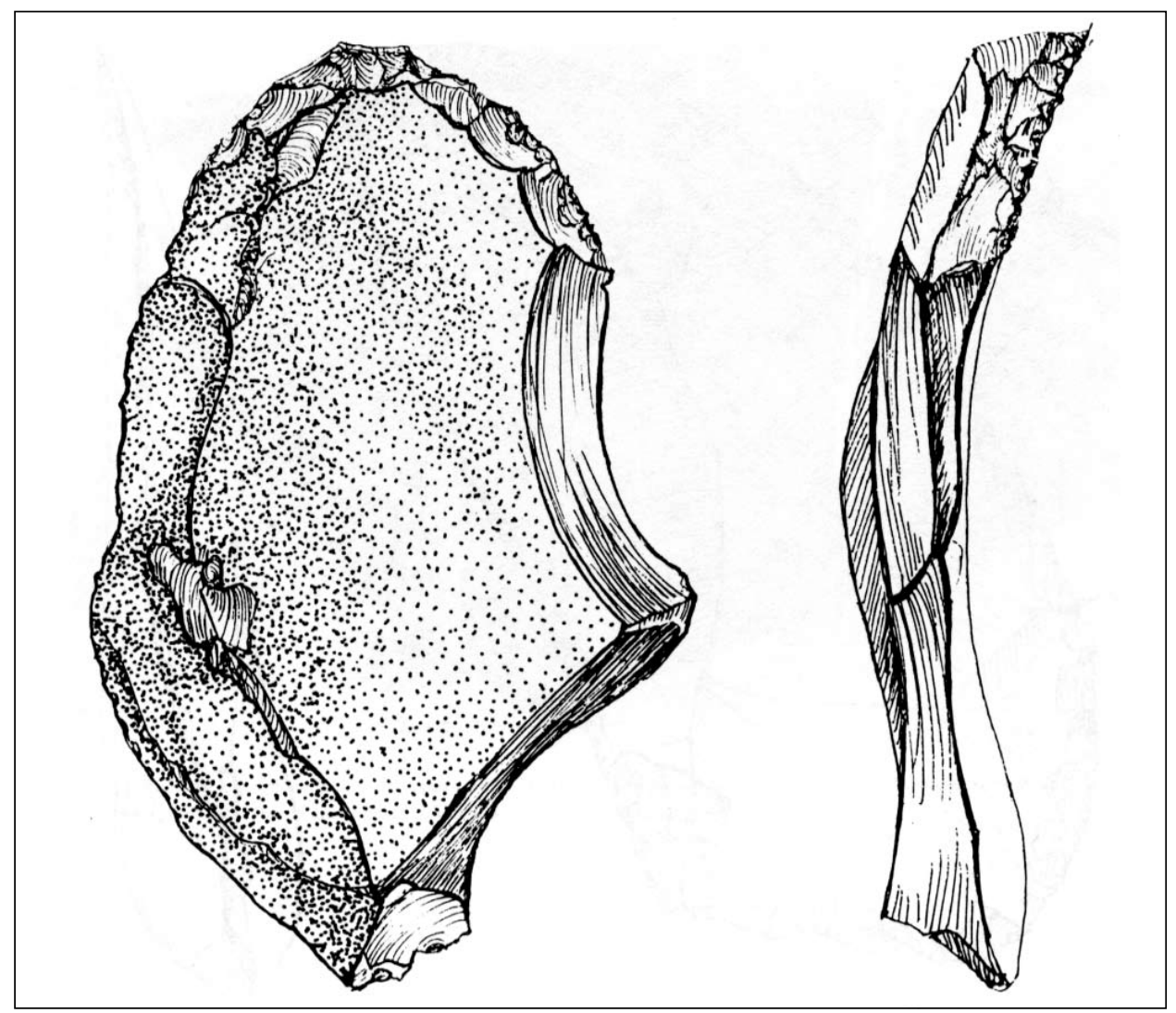

Figura 8. Raspador de borde activo menor que el ancho de la lasca, del Nivel 11, de Los Toldos. Tamaño natural.

y la etnografía, sino básicamente a otras ciencias y técnicas, que hoy están en creciente progreso. Este encuadre metodológico es consecuente con las opciones y consideraciones que señalamos en años anteriores (Cardich 1961: 47-53).
En tal virtud se programaron una serie de análisis, como por ejemplo, de $\mathrm{C}^{14}$, con el fin de fechar los diversos niveles culturales del perfil, y próximamente serán procesadas otras muestras extraídas en campañas más recientes. Se han llevado a cabo también 


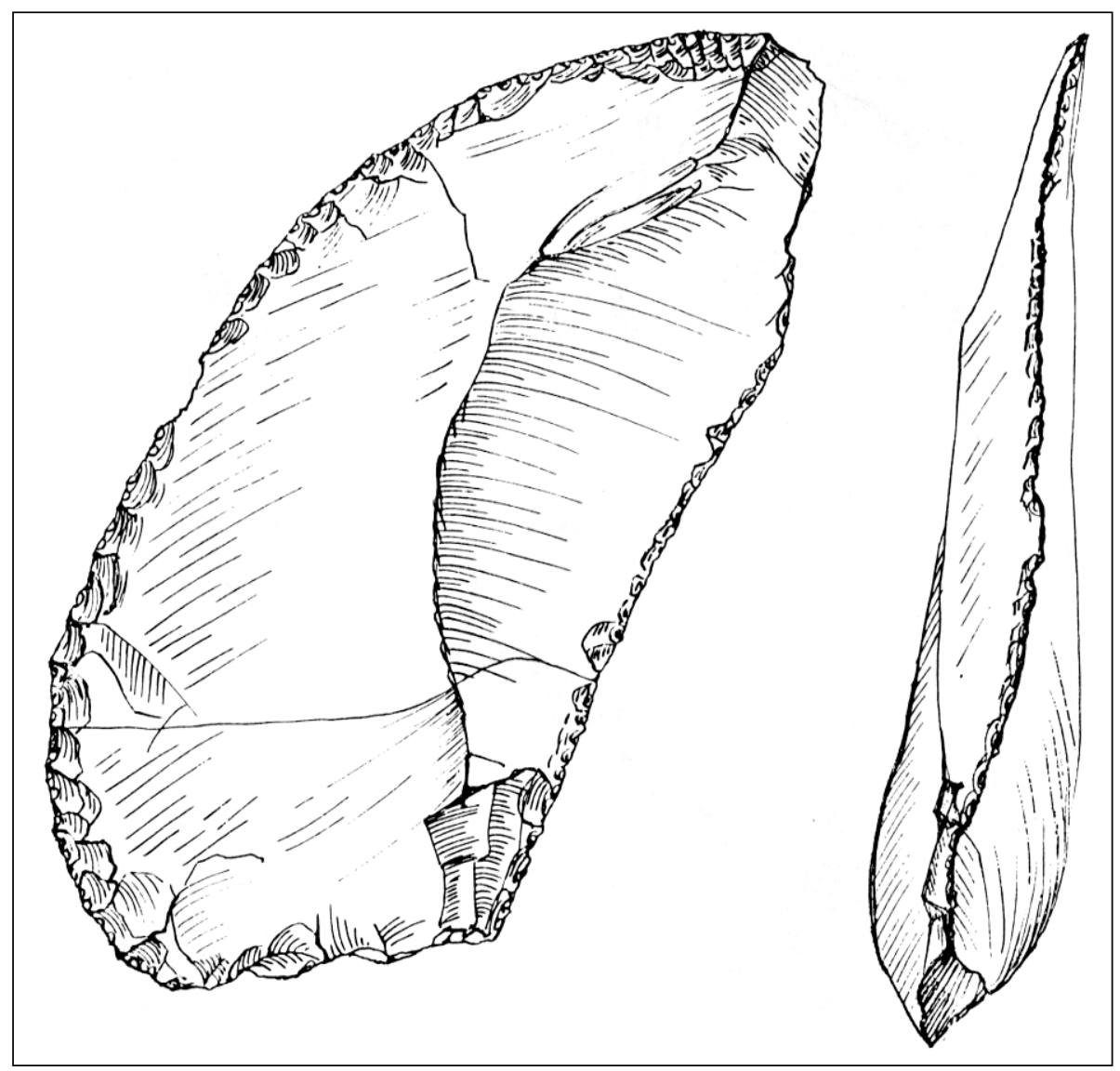

Figura 9. Cuchillo unifacial del Nivel 11 de Los Toldos. Tamaño natural.

análisis sedimentológicos con sus correspondientes interpretaciones a cargo de especialistas (Mazzoni y Spalletti 1974), a base de muestras de la Cueva 3, capa por capa, y de un perfil del valle contiguo. Actualmente está también en marcha un estudio palinológico a base de muestras de la secuencia de la Cueva 3.

A base de los numerosos fragmentos óseos de la Cueva 3 de Los Toldos, de las diferentes capas de su amplia secuencia, se ha realizado una investigación con la colaboración de Andrés Laguens (Cardich y Laguens 1984), sobre fractura intencional y posterior utilización de restos faunísticos óseos. La muestra comprende 8329 ejemplares, y el total de atributos tomados para cada ejemplar es de 47 , "que considerando las distintas posibilidades que presentan cada uno, y teniendo en cuenta la discriminación en borde izquierdo y derecho, extremo proximal y distal, y superficie interna y externa, llegan a contabilizar 308 atributos para cada ejemplar" (Cardich y Laguens 1984: 334). Los resultados muestran que no hay variación alguna en la fractura intencional (paralela, en espiral) y en la utilización posterior en tan larga secuencia, a pesar de que se determinaron marcadas diferencias en la industria lítica. Esto nos lleva a pensar que dadas sus características físicas, el hueso tiene limitaciones propias en cuanto a posibilidades distintas de fractura. Esta condición explicaría la cierta recurrencia en la aparición de estas fracturas tanto en contextos humanos como no humanos, como los ejemplares fracturados de edad terciaria (Myers et al. 1980), que pasarían como realizados por el hombre en otro contexto. Entre los huesos de los sitios de la provincia de Buenos Aires, como Cañada de Rocha, Arroyo Frías, estudiados por Ameghino (1880), por ejemplo, se observan las mismas variedades de fractura que en el material de Los Toldos. Parece ser, por otra parte, que para los cazadores de Los Toldos el hueso como materia prima ha tenido una importancia secundaria en sus industrias, pues habitaron un medio rico en materia lítica de excelente calidad, que muy hábilmente supieron trabajar. 
Otro aspecto que ha merecido nuestra atención ha sido el estudio de las huellas de utilización del instrumental lítico. Contamos con la colaboración de una especialista en el tema, la doctora Estela Mansur-Franchomme, quien participa como miembro de nuestro grupo de trabajo en investigaciones en Santa Cruz. Con respecto a este tema de estudios, cabe decir que el método más moderno de análisis de huellas de utilización ha sido desarrollado por Keeley, y perfeccionado y precisado por Anderson Gerfaud, Vaughan y Mansur-Franchomme. Se ha demostrado que los microlascados que se observan en los filos, frecuentemente atribuidos a la utilización de instrumentos, pueden resultar de otros fenómenos naturales o accidentales, y que por lo tanto no tienen un criterio válido para identificar la utilización. El único criterio funcional definitorio lo constituyen los micropulidos que, asociados a estrías microscópicas, permiten identificar los siguientes tipos de materiales trabajados: madera, plantas no leñosas, cuero seco, piel fresca, carne, asta o hueso, valva, etc. (Mansur-Franchomme 1981). Los micropulidos son alteraciones de la superficie criptocristalina del sílex o pedernal, debida a la disolución y recristalización de algunos componentes del sílex, producida durante la utilización. Estos micropulidos son sólo identificables cuando se trabaja a gran aumento, con microscopios adecuados. Se realizó la observación de los filos usando un microscopio Wild M20 de reflexión y un microscopio metalográfico Olympus PME, con aumentos que oscilan entre 250X y 500X; y un microscopio electrónico de balayage modelo ETEC-SIEMENS de cámara ancha para aumentos entre $3000 \mathrm{X}$ y $10000 \mathrm{X}$ y para análisis con microsonda de la composición de las zonas alteradas. El estudio de los materiales de la capa 12 de El Ceibo (Cardich el al. 1982), equivalente, como se ha señalado, al nivel 11 de Los Toldos, permitió extraer estas conclusiones: a) Todos los útiles estudiados, sin excepción, fueron utilizados en prehensión directa, sin ningún dispositivo de enmangue ni de protector manual; b) Todas las piezas observadas que tienen retoque y hasta una lasca sin retoque presentaron huellas de utilización; c) La mayor parte de las piezas observadas fueron utilizadas para trabajar pieles (frescas o secas) y para cortar carne, y sólo unos pocos para trabajar madera. No hay evidencias de otras actividades hasta el momento; d) La mayor parte de las piezas fueron utilizadas para trabajar un solo tipo de material, hay sólo tres casos de utilización doble; e) De los filos utilizados para corte de carne, ninguno muestra signos de haber atravesado tendones o tocado hueso, lo que indicaría que después de la matanza y descuartizamiento de los animales fuera de la cueva, ciertos trozos de carne eran traídos a la cueva junto con las piedras, y que en ella se desarrollaban las actividades domésticas.

Otras investigaciones correspondieron a las determinaciones zoológicas y paleontológicas de los restos óseos exhumados. Hemos contado con el apoyo de la División de Paleontología del Museo de La Plata, en un primer momento de los Dres. Rosendo Pascual y Oscar Odreman Rivas y, posteriormente, del Dr. Eduardo Tonni, a quienes expresamos nuestro agradecimiento. Colaboraron, asimismo, desde nuestro grupo de trabajo los licenciados Adam Hajduk, Néstor Kriscautzky, Andrés Laguens, y en la actualidad Laura Miotti. El hallazgo de huesos de perro (Canis familiaris) en Los Toldos dio lugar a un informe que fue publicado (Cardich et al. 1977); dicho descubrimiento se produjo en la cima de la capa 6 de la Cueva 3, esto es, al final del Casapedrense, como que estaban cubiertos en parte por la ceniza volcánica, nivel para el que tenemos la fecha radiocarbónica de 4850 años AP El estudio más detenido de los recursos faunísticos a base de los restos óseos ha sido encarado con la colaboración de L. Miotti (Cardich y Miotti 1983). A base de ciertos restos de aves de nuestra colección se han llevado a cabo también otros trabajos como los realizados por los paleontólogos Tambussi y Tonni (1985), con algunas inferencias sobre características paleoambientales de Los Toldos.

\section{Pinturas rupestres}

Existe buen número de pinturas rupestres en estas localidades estudiadas, como son las cavernas y reparos de Los Toldos y de El Ceibo, así como de la zona contigua de La María; muchas de estas pinturas muestran apreciable conservación de los diseños y colores, y en algunos sectores de las paredes se reúnen en forma profusa. Cabe recordar, por otra parte, la conocida riqueza en expresiones de arte rupestre que caracteriza a la Patagonia argentina, así como a la existencia de una cantidad cada vez más importante de publicaciones al respecto.

Nuestro interés en el estudio comienza con los primeros trabajos realizados en Los Toldos en el año 1971. Contamos, aparte de la bibliografía regional y general, con una modesta experiencia anterior en el arte rupestre de la zona de Lauricocha, en los Andes peruanos, que resumimos en el capítulo IV de nuestro segundo informe de Lauricocha (Cardich 
1964: 123-147). En la Patagonia continuamos en años posteriores con observaciones y relevamientos en la misma localidad de Los Toldos, y luego, en 1979, en El Ceibo y La María (Cardich 1979).

Uno de los aspectos que hemos tratado de considerar prioritariamente durante los estudios ha sido el de la cronología. Esto es, el de aproximarnos a conocer su antigüedad y los términos de su vigencia, y en lo posible la edad de sus principales modalidades estilísticas. Había un antecedente bibliográfico interesante, nos referimos a las estimaciones, mayormente tentativas de Menghin (1952, 1957), que al formular un cuadro de los estilos rupestres de la Patagonia los dispuso en secuencias dentro de un marco temporal que se iniciaría en el nivel Toldense, alcanzando su presencia hasta tiempos recientes.

En trabajos arqueológicos posteriores llevados a cabo por otros autores se han producido algunos hallazgos fortuitos que favorecen esta investigación. Así, en nuestras excavaciones en la Cueva 3 de Los Toldos en el año 1971 encontramos una porción de pintura roja en la capa 10 (Toldense antiguo), no es imposible que hubieran sido de las utilizadas para pintar los motivos rupestres; "asimismo se hallaron en la capa 10, dos fragmentos de roca del techo que parecen contener parte de un dibujo rupestre en rojo, que se habrían desprendido ya en aquellos lejanos tiempos" (Cardich et al. 1973: 96). Esto indicaría una antigüedad cercana a los 11000 años, y confirmaría la hipótesis de Menghin, aunque surgió también la probabilidad de que sea algo más antigua, pues en la capa 11a se encontró una porción de pintura amarilla, tal vez usada en estas obras rupestres.

Posteriores trabajos van a apoyar estas primeras evidencias. Entre éstos tenemos el aporte constituido por las determinaciones de los componentes mineralógicos de las mismas pinturas utilizadas en las obras rupestres de la Cueva de las Manos (estancia Alto Río Pinturas), al noroeste de la provincia de Santa Cruz (Iñíguez y Gradin 1977). Entre los componentes constantes de las pinturas rupestres figura un yeso hemihidratado, mezclado con los pigmentos, y este yeso no aparece en muestras de algunas superficies de roca coloreadas por oxidaciones naturales. Aparte, Gradin encontró en sus excavaciones y en la capa cultural más profunda (de características toldenses) fragmentos de roca con pinturas, y éstas, al análisis, mostraron también la presencia de yeso, lo que indica su calidad de pintura efectuada por el hombre. Como la capa tiene una edad determinada por $\mathrm{C}^{14}$ de 9330 años AP (Gradin et al. 1979; Gradin 1984), se puede inferir que cuando menos esta es la edad en que cayeron al piso de la cueva, desprendidos de las paredes, los fragmentos señalados de corteza de roca conteniendo pinturas rupestres.

Durante nuestras excavaciones y sondeos en los yacimientos de El Ceibo pudimos hallar también más testimonios sobre la antigüedad de esta tradición de pinturas rupestres. Así, hicimos sondeos en el piso del amplio reparo $\mathrm{n}^{\circ} 6$, estableciendo la cuadrícula B con un lado contra la roca de la pared vertical. La excavación alcanzó $1.10 \mathrm{~m}$ de profundidad en que se tocó la roca del piso, y en el perfil alternaban capas fértiles con otras estériles arqueológicamente. Esta cuadrícula B está a pocos metros de la Cueva 7, en la que encontramos una secuencia que incluye, como dijimos, industrias Toldenses y del nivel 11, además de otras industrias menos antiguas. En esta cuadrícula B hay también un perfil algo semejante al de la nombrada Cueva 7. En el estrato ubicado a $35-45 \mathrm{~cm}$ encontramos, entre otros, dos piezas de típica factura casapedrense. Ahora bien, en la pared rocosa, al separar los sedimentos durante la excavación, se hallaron motivos de pintura rupestre representando dos guanacos en rojo oscuro. La profundidad máxima que tocan las pinturas es de $80 \mathrm{~cm}$ (Figura 10), y de acuerdo a este nivel no pudieron ser pintadas sino por los Toldenses o por los ocupantes del nivel 11. Naturalmente, es un testimonio para considerar con esa antigüedad a algunas de las pinturas del sitio, no a todas, pues hay claros indicios de una larga vigencia de esta tradición de pinturas rupestres.

Otro de los aspectos de nuestro interés ha sido el tema de la monocromía o policromía de las pinturas, tema sobre el que nos hemos ocupado también anteriormente (Cardich 1979).

En las cavernas y reparos de Los Toldos hay, como dijimos, numerosas pinturas, entre las cuales predominan los negativos de manos (Figuras 11 y 12) y muy pocas representaciones que se apartan de esta modalidad. Los negativos de manos corresponderían a prácticas de larga vigencia en la zona, pues se advierten en algunos paneles superposiciones de pinturas, así como yuxtaposiciones con distinto grado de conservación. Se puede inferir también que algunas pinturas serían ya postcasapedrenses, como las del techo del recinto oscuro de la Cueva 3, que se plasmaron sobre el negro del hollín, y de acuerdo a los trabajos excavatorios en el piso de dicho recinto 
sabemos que fueron ocupados densamente por los Casapedrenses y no por otros grupos anteriores, $y$ la capa de hollín en todo el techo probablemente se formó durante dicha ocupación.

En El Ceibo y en La María hay mayor variedad de motivos, aunque también están presentes los negativos de manos, y, ante todo, las figuras de guanacos, algo de ñandú (Figuras 13, 14 y 15), así como escasas, muy esquematizadas y pequeñas representaciones humanas. Aparecen además pocas figuras de otros animales, también de pinturas no figurativas y de carácter geométrico. Entre las figuras de guanacos son relevantes las que presentan animales con el cuerpo abultado como de hembras preñadas. Las pinturas mejor logradas están entre las más antiguas, y junto a éstas destacan las figuras de un felino, en rojo y con pintas negras, que hemos encontrado en El Ceibo, en un número de cuatro. El que mejor se conserva por estar plasmado en el techo de la Cueva $6 \mathrm{~b}$ (Figuras 16 y 17), es una figura dominante ocupando el centro del panel. El carácter naturalístico de la pintura nos muestra algunos rasgos característicos del animal representado: tendría, por ejemplo, la cola corta y un pelo mucho más crecido cubriría el sector de su cruz. Estos rasgos no corresponden al jaguar actual (ni otro felino viviente), empero algunos hallazgos en la región austral de Sudamérica, de restos de un felino de gran tamaño, hoy extinto, nos han proporcionado una pista para realizar mayores aproximaciones y plantear la posibilidad de relacionar dicha subespecie extinta con estas expresiones de arte rupestre de El Ceibo (Cardich 1979). En efecto, estos descubrimientos se produjeron en la llamada Cueva del Milodón, de la región austral de Chile, que es un enorme recinto y cuyos rellenos sedimentarios del piso se fueron depositando a partir del retiro del hielo, esto es, con posterioridad a los 14000 años AP, de acuerdo a estudios realizados por especialistas y a las dataciones radiocarbónicas. En los sedimentos de esta caverna se han hallado capas conteniendo restos de fauna y asimismo algunos elementos culturales. Transcribimos párrafos de un trabajo anterior para referirnos a este punto (Cardich 1979: 177, 178):

"Entre los huesos de animales extinguidos que se hallaron en la gruta del Milodón figuran huesos de la forma fósil de jaguar; de uno de los hallazgos, del realizado por $R$. Hauthal y que se conserva en el Museo de La Plata, se ha tomado como tipo el cráneo número 10-90 por el paleontólogo Ángel Cabrera, quien propuso el nombre de Panthera onca mesembrina, con que se conoce científicamente en la actualidad. Ya las primeras mediciones de los huesos realizadas por Santiago Roth (1902: 6) determinaron el gran tamaño del ejemplar que 'se acerca al tamaño del león de Africa'. Estas características del gran jaguar extinguido dieron la certeza para que el

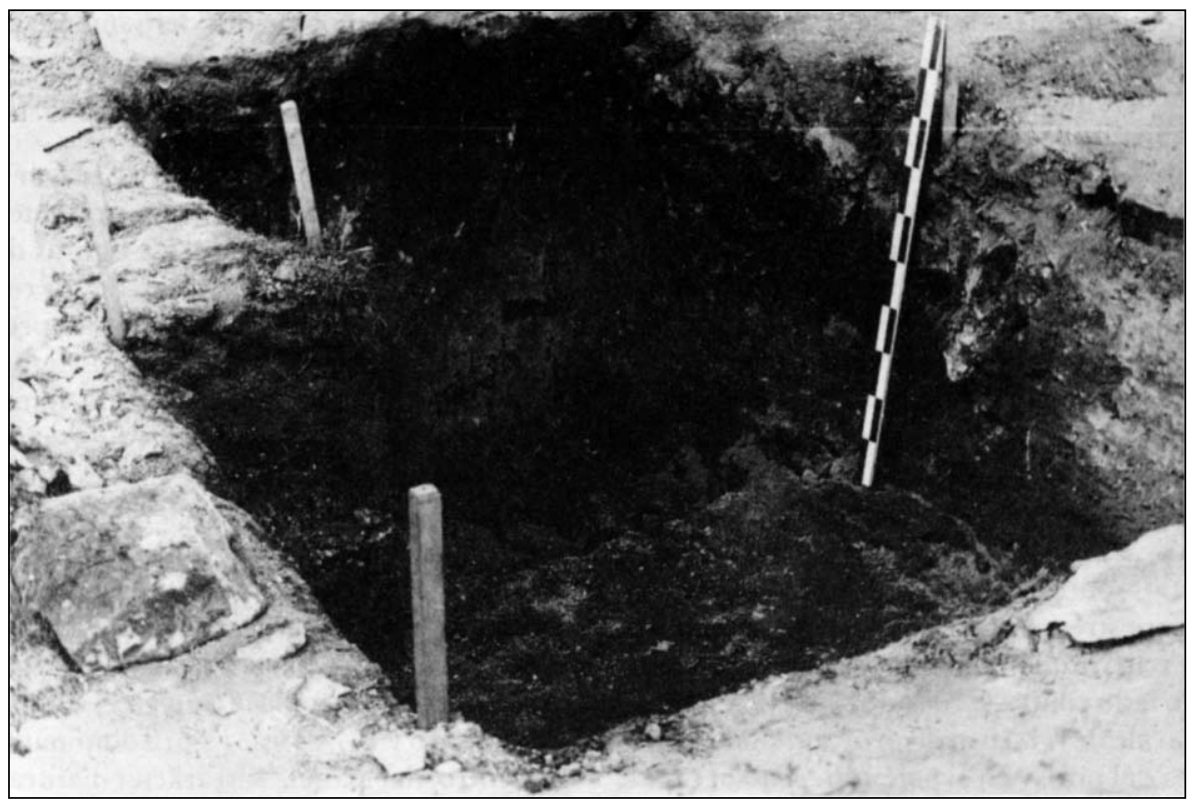

Figura 10. Vista de la cuadrícula B excavada en la base del reparo 6 de El Ceibo. Al separar los sedimentos aparecieron en la pared rocosa dos motivos rupestres en rojo oscuro, representando guanacos. Por el nivel hasta donde desciende, se aprecia su gran antigüedad. 


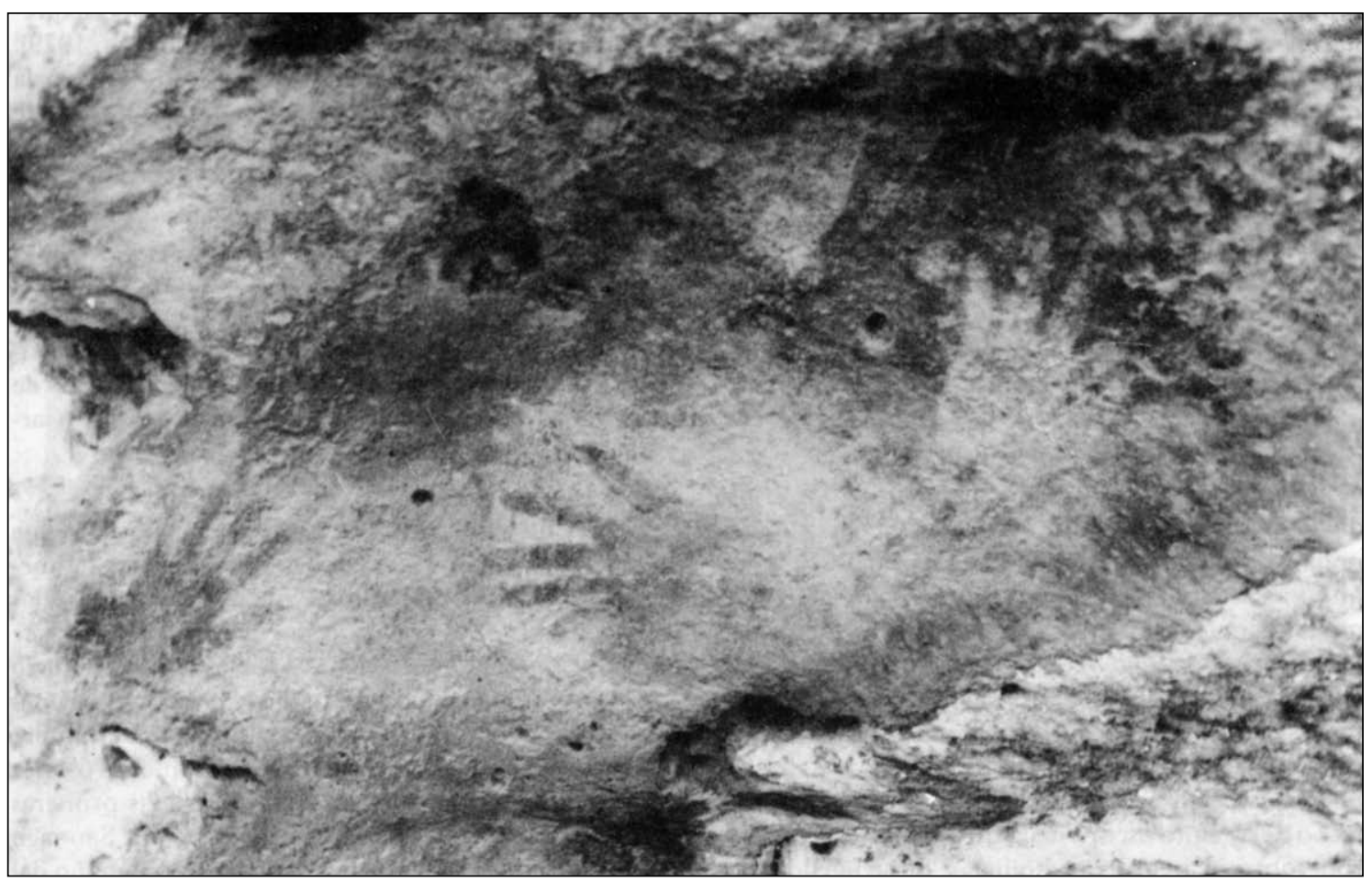

Figura 11. Pinturas de negativos de manos en varios colores, de la Cueva 2 de Los Toldos.

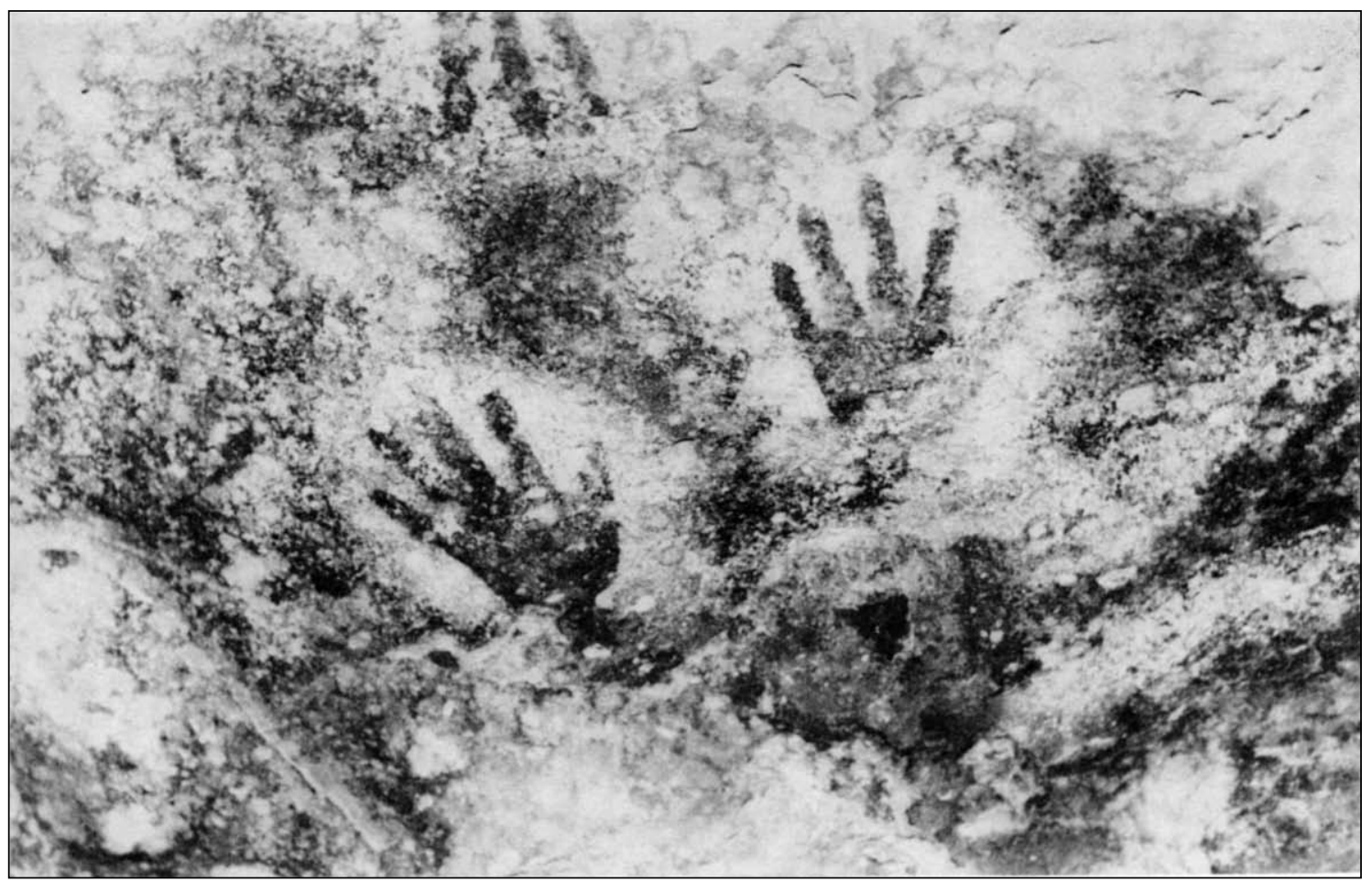

Figura 12. Negativos de manos en el techo de la Cueva 3 de Los Toldos. 


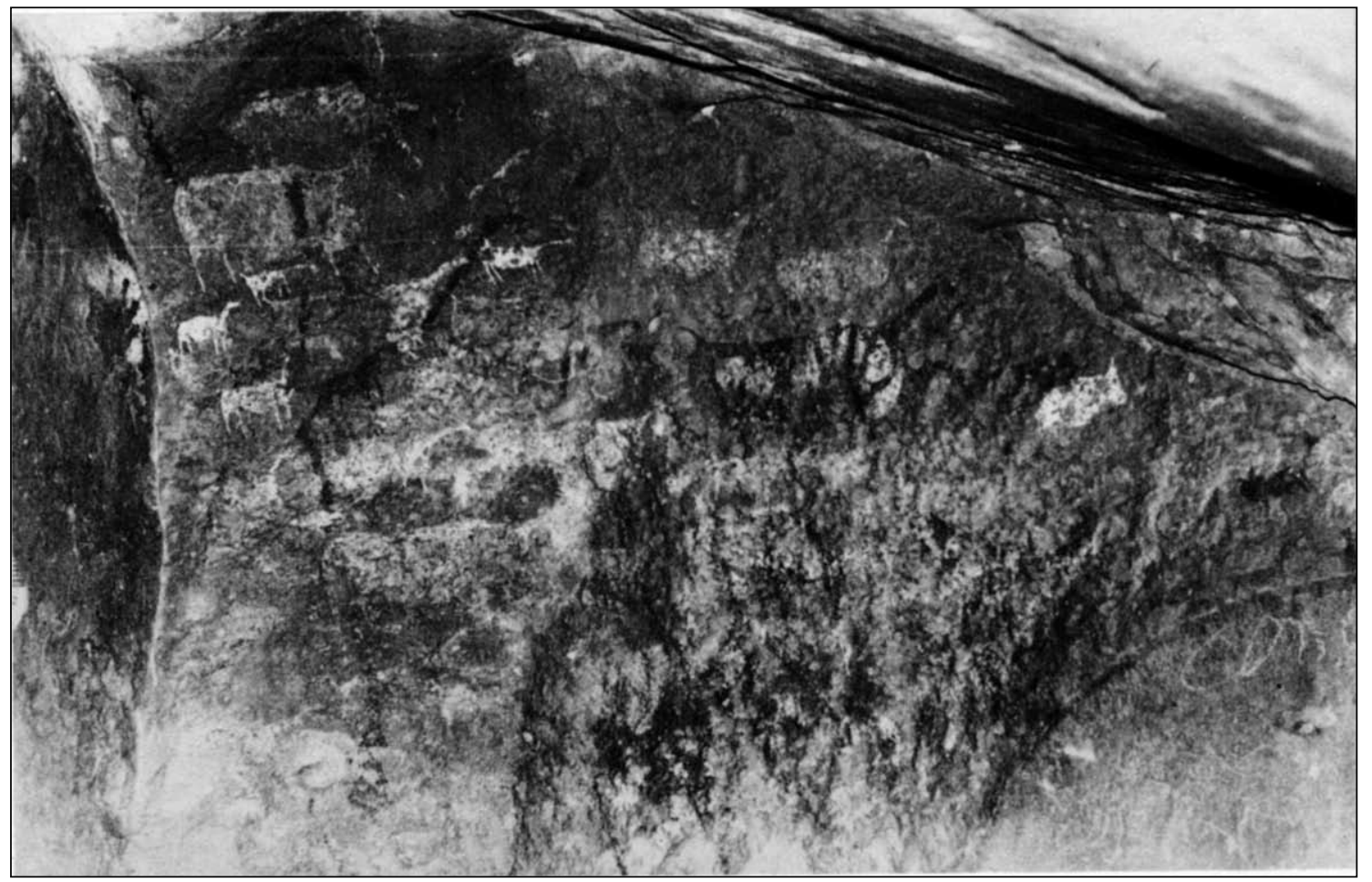

Figura 13. Conjunto de pinturas de la Cueva $6 \mathrm{~b}$ de El Ceibo.

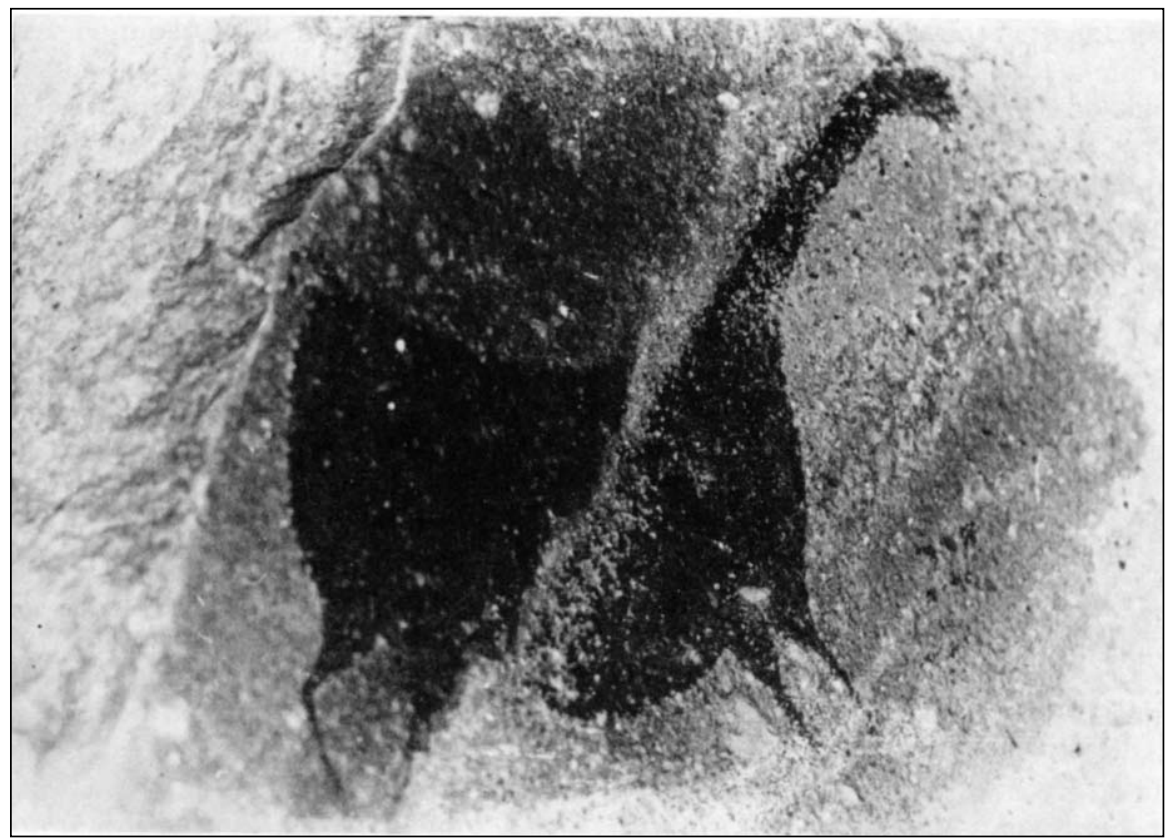

Figura 14. Figura de guanaco estilizado de El Ceibo. 


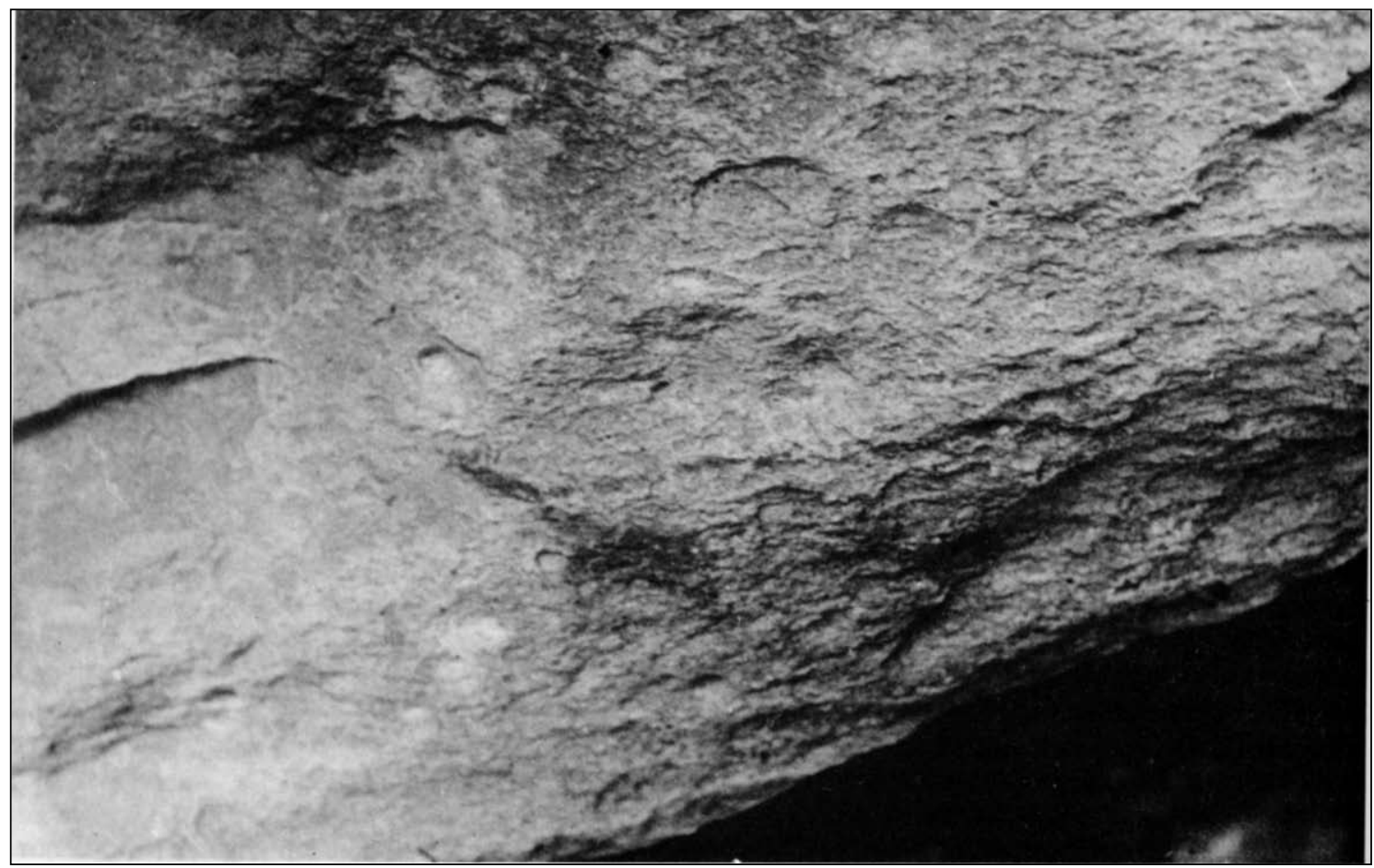

Figura 15. Testimonio rupestre del uso del lazo, un guanaco tomado por un lazo del pescuezo tratando de huir.

Dr. Cabrera (Cabrera, 1933: 27) señalara que 'el tigre americano ha estado en otro tiempo representado en altas latitudes por una raza gigante, que era para su especie lo que es para el tigre real la subespecie siberiana, o lo que fue respecto de Leo leo la forma europea de L. speleaus"”.

Sobre la posible edad de esta subespecie de felino fósil de la Cueva del Milodón, se puede conjeturar que al retiro de los glaciares de toda la región, y cuando la fauna se iba estructurando luego de los primeros pasos de la colonización, habría llegado desde territorios libres del hielo de la Patagonia argentina el jaguar gigante, esto es, podemos estimar, alrededor de hace 13000 años. Sobre el momento en que se extingue poco se sabe, aunque es presumible que haya estado presente en esta región austral por un buen tiempo, y hasta no es imposible, como también considera Cabrera (1933: 26), que esta subespecie es la que habría existido en la Patagonia hasta tiempos más o menos tardíos. Consideramos pertinente transcribir más párrafos de nuestro trabajo anterior sobre el tema (Cardich 1979: 179):

"Ahora bien, dijimos arriba que el hombre estuvo ya en Los Toldos alrededor de 12600 años AP, y que posiblemente en fecha no muy alejada arribó a El Ceibo y sabemos en base a las dataciones obtenidas para la Cueva Fell, el hombre ya estaba en Magallanes hace 11000 años, sin excluir el posible arribo anterior de otras líneas de poblamiento. Por estos datos que apuntan a una contemporaneidad, resulta altamente posible que estos antiguos grupos humanos hubieran conocido a ese enorme jaguar que habitó en la región austral de Sudamérica, como conocieron a los otros dos elementos de la megafauna: el caballo y el milodón. Hay otros aspectos también sugestivos al respecto: entre los restos de este felino obtenidos en la Gruta del Milodón y que llegaron al Museo de La Plata, figura un retazo de piel ( $\left.n^{\circ} 1533\right)$ sobre el que describe Santiago Roth (1902: 6): 'el pelo del pedacito de piel adherido a la cara conserva su color natural, y este color castaño luciente tira un poco a rojizo. Esto indica que (...) ha sido un gato de hermosos colores', que consignamos por coincidir aproximadamente con el color de la pintura. Además hay otro dato valioso, que sumado a los otros indicios, puede ser casi definitorio, y es que en el cráneo-tipo elegido como representante de esta Panthera onca mesembrina según Cabrera (1933: 25) 'hay un detalle curioso, del que no hizo mención Roth; el maxilar izquierdo presenta, justamente al lado del respectivo nasal, una perforación de un centímetro de diámetro, que pasa el hueso de parte 


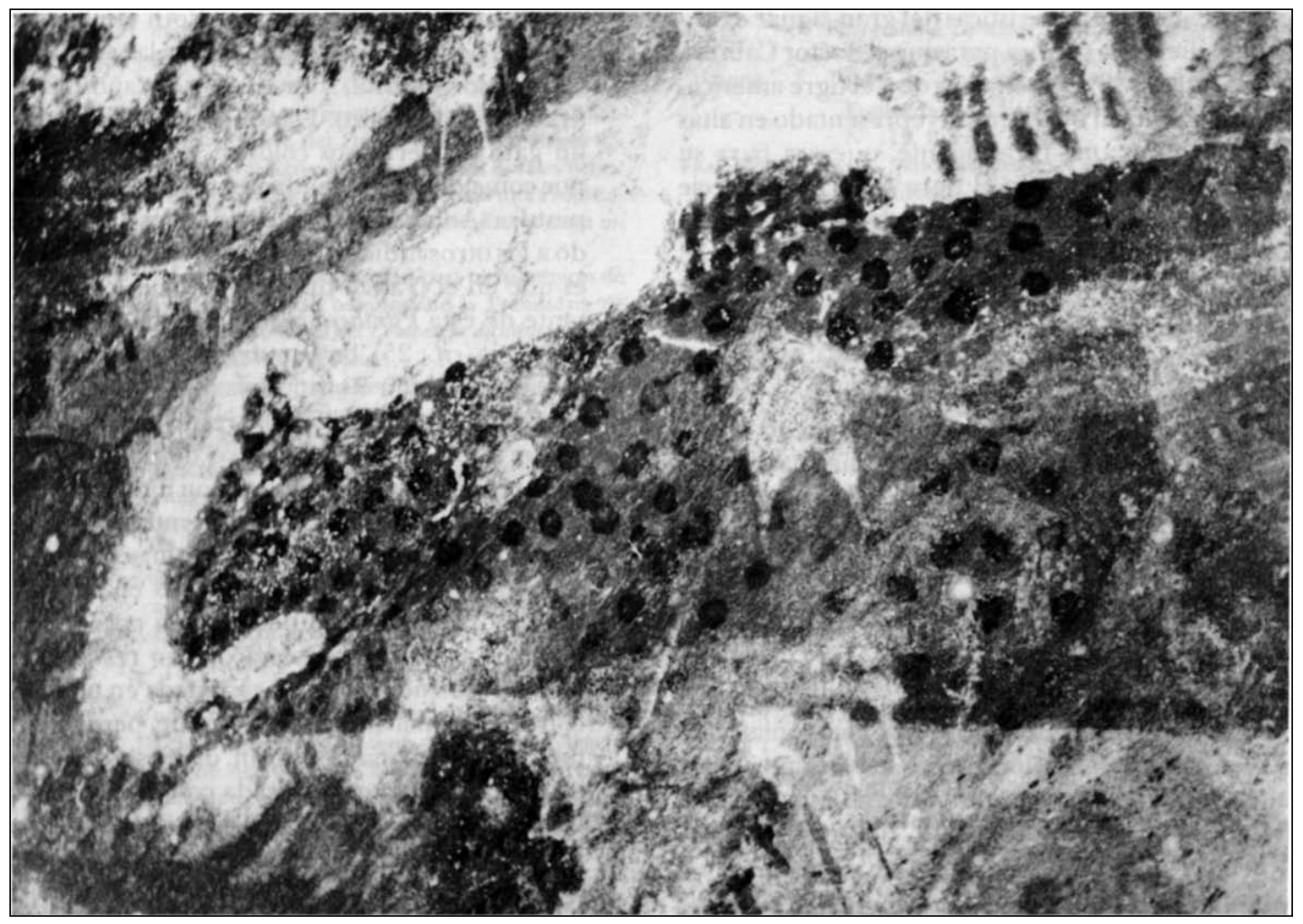

Figura 16. La parte anterior de la figura del felino, tomada con película infrarroja. Cueva $6 \mathrm{~b}$ de El Ceibo.

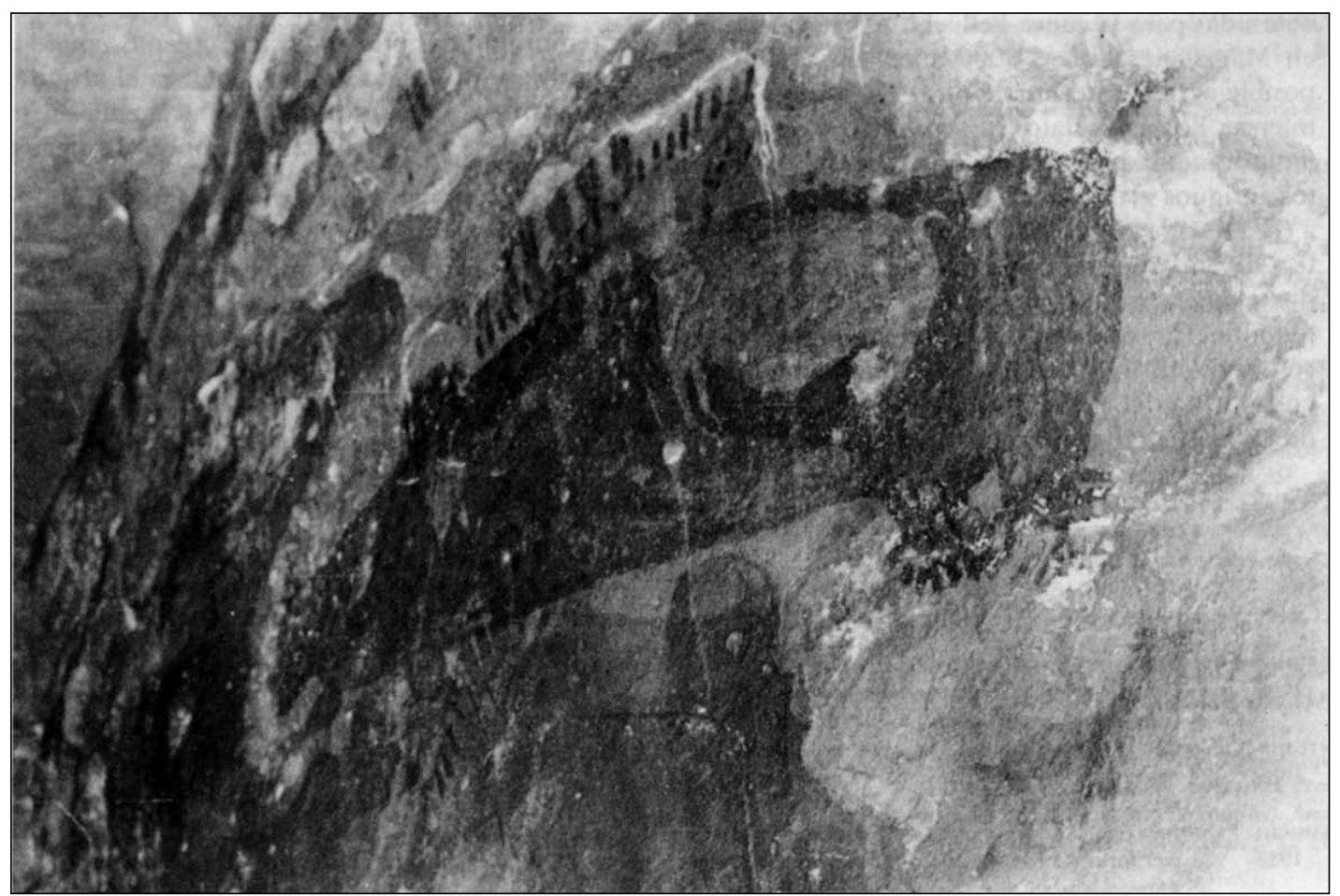

Figura 17. Vista desde la parte posterior del felino para observar la cola corta. Cueva $6 \mathrm{~b}$ de El Ceibo. 
a parte con indicios evidentes de necrosis y curación con formación de callo. Como por lo demás se trata de un cráneo muy sano y de avanzada edad (suturas en su mayor parte borradas), dicha perforación no parece de origen puramente patológico, sino resultado de una herida que pudo ser ocasionada en una lucha con otro animal de la misma especie, pero que más bien, por su forma y posición, debió ser hecha con un arma punzante impulsada con gran violencia: acaso la punta de piedra de una flecha o de una lanza'...Las consideraciones anotadas permiten, pues, señalar la gran posibilidad de que un ejemplar de esta subespecie de gigantesco jaguar, hoy extinguido, esté representado en el dibujo de El Ceibo que hemos estado tratando. Esto tanto más posible si se hubiera realizado en el Holoceno Temprano, período en el cual, creemos, pudo haber tenido más acentuada vigencia el arte de la pintura y, además, teniendo en cuenta en una probable persistencia hasta entonces de dicha subespecie fósil".

Podemos concluir anotando que las más antiguas pinturas de manos en negativo y algunas figuras de guanacos junto con las pinturas del jaguar gigante (Panthera onca mesembrina), estarían entre las expresiones de mayor edad en El Ceibo, y corresponderían, de acuerdo a todos los indicios, a una tradición de los paleoindios de esta parte de América.

\section{REFERENCIAS CITADAS}

AMEGHINO, F., 1880. La antigüedad del hombre en el Plata. Obras completas y correspondencia científica, vol. 3, Gob. Pcia. Buenos Aires, La Plata, 1915.

— 1889. Los mamíferos fósiles de la República Argentina. Academia Nacional de Ciencias, vol. 6: I-XXXII, Buenos Aires.

APARICIO, F. DE, 1933. Viaje preliminar de exploración en el territorio de Santa Cruz. Publicaciones del Museo Antropológico y Etnográfico, Facultad de Filosofía y Letras, Serie A, vol. 3, Buenos Aires.

AUER, V., 1950. Las capas volcánicas como base de la cronología postglacial de Fuegopatagonia. Ministerio de Agricultura de la Nación, Revista de Investigaciones Agrícolas 3 (2), Buenos Aires.

1956. The Pleistocene of Fuego Patagonia, Part I: The Ice an Interglacial ages. Annales Academiae Scientorum Fennicae, 3 (60), Helsinki.

BIRD, J., 1970. Paleo-indian discoidel stones from SouthernSouth America. American Antiquity 35 (2).

CABRERA, A., 1933. Los yaguares vivientes y extinguidos de la América Austral. Notas preliminares del Museo de La Plata, vol. 2. La Plata.

CABRERA, A. L. y A. WILLINK, 1975. Biogeografía de América Latina. Monografías número 13, O.E.A., Washington D. C.

CALDENIUS, C., 1932. Las glaciaciones cuaternarias en la Patagonia y Tierra del Fuego. Publicación 95. Ministerio de Agricultura de la Nación, Buenos Aires.

CARDICH, A., 1964. Lauricocha. Fundamentos para una prehistoria de los Andes Centrales. Studia Praehistorica III, Buenos Aires.

1977. Las culturas pleistocénicas y post-pleistocénicas de Los Toldos y un bosquejo de la prehistoria de Sudamérica. Obras del Centenario del Museo de La Plata vol. 2, La Plata.
— 1977a. Datierung der jungpleistozänen Vereisung Lauricocha in den Peruanischen Anden. Geologischen Rundschau, Band 66, Stuttgart.

— 1978. Descripción y tipología de las industrias líticas más antiguas de Los Toldos. Relaciones de la Sociedad Argentina de Antropología XII.

— 1978a. Recent excavations at Lauricocha (Central Andes) and Los Toldos (Patagonia). Early Man in America, A. L. Bryan (Ed.), University of Alberta, Edmonton.

-1979. A propósito de un motivo sobresaliente en las pinturas rupestres de El Ceibo (provincia de Santa Cruz, Argentina). Relaciones de la Sociedad Argentina de Antropología XIII, Buenos Aires.

_ 1984. Paleoambientes y la más antigua presencia del hombre. Comisión Nacional para la celebración del V Centenario del Descubrimiento de América, Biblioteca del $\mathrm{V}$ Centenario, Madrid.

— 1985. Una fecha radiocarbónica más de la Cueva 3 de Los Toldos (Santa Cruz, Argentina). Relaciones de la Sociedad Argentina de Antropología XVI.

CARDICH, A. y L. MIOTTI, 1978. Recursos faunísticos en la economía de los cazadores recolectores de Los Toldos (provincia de Santa Cruz, Argentina). Relaciones de la Sociedad Argentina de Antropología XV.

CARDICH, A. y A. LAGUENS, 1984. Fractura intencional y posterior utilización del material óseo arqueológico de la Cueva 3 de Los Toldos, provincia de Santa Cruz, Argentina. Revista del Museo de La Plata VIII (63).

CARDICH, A., L. A. CARDICH y A. HAJDUK, 1973. Secuencia arqueológica y cronología radiocarbónica de la Cueva 3 de Los Toldos (Santa Cruz, Argentina). Relaciones de la Sociedad Argentina de Antropología VII.

CARDICH, A., E. P. TONNI y N. KRISCAUTZKY, 1977. Presencia de Canis familiaris en restos arqueológicos de Los 
Toldos (provincia de Santa Cruz, Argentina). Relaciones de la Sociedad Argentina de Antropología XI.

CARDICH, A., M. E. MANSUR-FRANCHOMME, M. GIESSO, V. DURAN, 1982. Arqueología de las cuevas de "El Ceibo". provincia de Santa Cruz, Argentina. Relaciones de la Sociedad Argentina de Antropología XIV.

FIDALGO, F., 1973. Consideraciones sobre los bajos situados al norte de la provincia de Santa Cruz, Actas del $5^{\circ}$ Congreso Geológico Argentino vol. 5. Buenos Aires.

FLINT, R. y F. FIDALGO, 1963. Geología glacial de la zona de borde entre los paralelos $39^{\circ} 10^{\prime}$ y $41^{\circ} 20^{\prime}$ Lat. S en la Cordillera de los Andes, República Argentina. Dirección Nacional de Geología y Minería Bol. 93, Buenos Aires.

— 1968. Drift glacial al este de los Andes entre Bariloche y Esquel. Instituto Nacional de Geología y Minería, Bol. 119, Buenos Aires.

FRAY, C. y M. EWING, 1963. Wisconsin sea level as indicated in Argentine continental sheld. Proceeding Academy of Natural Sciences of Philadelphia 115.

GRADIN, C., 1984. Arqueología y arte rupestre de los cazadores prehistóricos de Patagonia. Comisión Nacional para la celebración del V Centenario de América. Biblioteca del V Centenario, Madrid.

GRADIN, C., C. ASCHERO, A. M. AGUERRE, 1979. Arqueología del área Río Pinturas (provincia de Santa Cruz). Relaciones de la Sociedad Argentina de Antropología XIII.

HEUSSER, C. J., 1983. Quaternary palynology of Chile. Quaternary of South America and Antarctic Peninsula vol. 1. J. Rabassa (Ed.), A.A. Balkema Rotterdam.

HEUSSER, C. J. y S. STREETER, 1980. A temperature and precipitation. Record of the last 16000 years in SouthernChile. Science 210.

IÑIGUEZ, A. M. y C. GRADIN, 1977. Análisis mineralógico por difracciones de rayos $\mathrm{X}$ de muestras de pinturas de la Cueva de las Manos, estancia Alto Río Pinturas. Relaciones de la Sociedad Argentina de Antropología XI.

MANSUR-FRANCHOMME, M. E., 1981. Microwear analysis of naturel and use strations: New clues to the mechanisms of stration formation. En F. Van Noten y D. Cahen (Eds.). Recent progress, in microwear studies Tervuren.

- 1984. Préhistoire de Patagonie L'industrie nievel 11 de la province de Santa Cruz, Argentine. BAR International Series 216, Oxford.

MAZZONI, M. M. y L. A. SPALLETTI, 1974. Sedimentología de la cueva de Los Toldos, provincia de Santa Cruz. Revista de la Asociación Argentina de Mineralogía, Petrología y Sedimentología V (1-2).

MENGHIN, O., 1952. Fundamentos cronológicos de la prehistoria de Patagonia. Runa V, Buenos Aires.

— 1957. Estilos del arte rupestre de Patagonia. Acta Praehistorica 1, Buenos Aires.

MERCER, J., 1970. Variations of some Patagonian glaciers since the Late-Glacial: II. American Journal of Science 269.

- 1972. Chilean glacial chronology 20000 to $11000 \mathrm{C}^{14}$ year ago. Some global comparisons. Science 176.

— 1976. Glacial History of Southernmost South America. Quaternary Researchs 6.

MYERS, T. P., M. R. VOORHIES y R. G. CORNER, 1980. Spiral fractures and bone pseudotools at paleontological sites. American Antiquity 45 (3).

NAVAS, J. y N. BO, 1981. Nuevas aportaciones a la taxonomía de las razas geográficas de Eudromia elegans y Eudromia formosa. Revista del Museo Argentino de Ciencias Naturales B. Rivadavia, Zod. 11 (2).

PORTER, S. C., 1981. Pleistocene glaciation in the Southern Lake District of Chile. Quaternary Research 16.

ROTH, S., 1902. Nuevos restos de mamíferos de la Caverna Ebernhardt en Ultima Esperanza, Revista del Museo de La Plata XI.

TAMBUSSI, C. P. y E. P. TONNI, 1985. Aves del sitio arqueológico Los Toldos, cañadón de las Cuevas, provincia de Santa Cruz (República Argentina). Ameghiniano (Rev. Asoc. Paleontol. Argent.) 22 (1-2). 
